Aus der Abteilung Zelluläre und Molekulare Immunologie (Prof. Dr. rer. nat. J. Wienands)

im Zentrum Hygiene und Humangenetik

der Medizinischen Fakultät der Universität Göttingen

\title{
Die Organisation von Signalnetzwerken in B-Lymphozyten
}

\section{INAUGURAL - DISSERTATION}

\author{
zur Erlangung des \\ Doktorgrades \\ der Medizinischen Fakultät der \\ Georg-August-Universität zu Göttingen \\ vorgelegt von
}

\section{Thomas Oellerich}

aus

Hannover

Göttingen 2011 
Dekan: Prof. Dr. med. C. Frömmel

I. Berichterstatter: Prof. Dr. rer. nat. J. Wienands

II. Berichterstatter/in: Prof. Dr. rer. nat. M. Thumm

III. Berichterstatter/in:

Tag der mündlichen Prüfung: 17.07.2012 


\section{Inhaltsverzeichnis}

I Abkürzungen

II Symbole für Aminosäuren

$\begin{array}{ll}\text { 1. Einleitung } & 1\end{array}$

1.1 Die B-Zell-Entwicklung: Vom prä-BZR zum Antikörper 1

1.2 Die BZR-abhängige Signaltransduktion in aktivierten B-Zellen 3

1.3 Die Rolle und Funktion von Adapterproteinen in der intrazellulären Signalleitung 6

1.4 Die SLP-Familie: Zentrale Adapterproteine in der BZR- und TZR-vermittelten

$\begin{array}{ll}\text { Signalleitung } & 7\end{array}$

2. Funktionelle Proteomics und BZR-vermittelte Signaltransduktion 10

2.1 Analyse der SLP65-Phosphorylierung 12

2.2 Relative Quantifizierung von Phosphopeptiden mittels SILAC 13

2.3 Phosphorylierung von Serin 173 in SLP65 ist notwendig für die p38- und JNK-

Aktivierung

2.4 Spezifische Identifikation von Protein-Protein-Interaktionen mittels quantitativer

Massenspektrometrie

2.5 Die Dynamik der SLP65-mediierten Protein-Protein-Interaktionen in Abhängigkeit von der BZR-Stimulation

2.6 Die Funktion der präformierten Interaktion von CIN85/CD2AP und SLP65

3. Diskussion der Ergebnisse

4. Literaturverzeichnis 


\section{Publikationen als Teil dieser Dissertation:}

A. Oellerich T, Gronborg M, Neumann K, Hsiao H, Urlaub H, Wienands J (2009): "SLP-65 phosphorylation dynamics reveals a functional basis for signal integration by receptor-proximal adaptor proteins." Mol Cell Proteomics $\underline{8}(7)$ : 1738-1750

B. Neumann K, Oellerich T, Urlaub H, Wienands J (2009): "The B-lymphoid Grb2 interaction code." Immunol Rev 232: 135-149

C. Oellerich T, Bremes V, Neumann K, Bohnenberger H, Dittmann K, Hsiao H, Engelke M, Schnyder T, Batista F, Urlaub H, Wienands J (2011): "The B cell antigen receptor signals through a preformed transducer module of SLP65 and CIN85." EMBO J 30(17): 3620-3634

D. Weitere Publikationen zu diesem Thema:

Bohnenberger H*, Oellerich T*, Engelke M, Hsiao HH, Urlaub H, Wienands J (2011): "Complex phosphorylation dynamics control the composition of the Syk interactome in B cells." Eur J Immunol 411(6): 1550-1562

Schnyder T, Castello A, Feest C, Harwood NE, Oellerich T, Urlaub H, Engelke M, Wienands J, Bruckbauer A, Batista FD (2011): "B cell receptor-mediated antigen gathering requires ubiquitin ligase $\mathrm{Cbl}$ and adaptors Grb2 and Dok-3 to recruit dynein to the signaling microcluster." Immunity $\underline{34(6): 905-9218}$

Sela M, Bogin Y, Beach D, Oellerich T, Lehne J, Smith-Garvin JE, Okumura M, Starosvetsky E, Kosoff R, Libman E, et al. (2011): "Sequential phosphorylation of

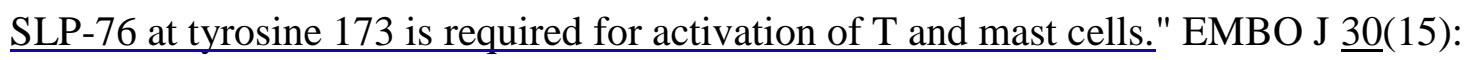
3160-3172

Neumann K, Oellerich T, Heine I, Urlaub H, Engelke M (2011): "도 gamma receptor IIb modulates the molecular Grb2 interaction network in activated B cells." Cell Signal 23(5): 893-900

* „equal contribution“ 


\section{Abkürzungen}

ALL Akute lymphatische Leukämie

a.m.u.

atomic mass units

AP

Affinitätspräzipitation

AP-1

Activator Protein 1

BASH

B cell adaptor containing SH2 domain

Blk

B lymphocyte kinase

BLNK

B cell linker protein

Btk

Bruton's Tyrosin-Kinase

BZR

B-Zell-Antigenrezeptor (und Plural)

CapZ

F-actin-capping protein

$\mathrm{Cbl}$

casitas B cell-lineage lymphoma

CD2AP

CD2-associated Protein

cDNA

complementary DNA

ch

chicken

CIN85

Cbl-interacting protein of $85 \mathrm{kDa}$

CLEC

c-type lectin domain family member

Clnk

cytokine-dependent hematopoietic cell linker

DAG

Diacylglycerol

Dok-3

Docking protein 3

1D-PAGE

eindimensionale Polyacrylamid-Gelelektrophorese

EGFR

epidermal-growth-factor-receptor

Erk

Extracellular signal-regulated kinase

FACS

fluorescene-activated cell sorter

GFP

Green fluorescent protein

Grb2

growth factor receptor-bound protein 2

HPK-1

hematopoietic progenitor kinase-1

$\mathrm{Ig}$

Immunglobulin

IP

Immunpräzipitation

ITAM

immunoreceptor tyrosine-based activation motif (und Plural)

JNK

c-Jun N-terminal kinase

$\mathrm{kDa}$

Kilodalton

LAT

Linker of activated T-cells

LTQ

linear trap quadrupole

Lyn

Lck/yes-related novel kinase

MAPK

mitogen-activated protein kinase 
millimolar

$\mu \mathrm{M}$

micromolar

Nck non-catalytic region of tyrosine kinase adaptor protein nuclear factor of activated T-cells

$\mathrm{NF \kappa B}$ nuclear factor kappa-light-chain-enhancer of activated B cells Polymerase-Kettenreaktion

$\mathrm{PH}$ pleckstrin homology

PI3K Phosphatidylinositol-3-Kinase

PIP3 Phosphatidylinositol-3,4,5-trisphosphat

PKC Proteinkinase $\mathrm{C}$

PLC- $\gamma 1 / 2 \quad$ Phospholipase C- $\gamma 1 / 2$

prä-BZR prä-B-Zell-Antigen-Rezeptor (und Plural)

PTB Phosphotyrosine-binding

PTP-Pest Tyrosine-protein phosphatase non-receptor type 12

PTPR-alpha Receptor-type tyrosine-protein phosphatase alpha

Ras zusammengesetztes Akronym aus Rat sarcoma

Raf

Sek-1 zusammengesetztes Akronym aus rapidly growing fibrosarcoma

$\mathrm{SH}$ sapk/erk kinase protein 1

SHIP Src-homology region

SILAC phosphatidylinositol-3,4,5-trisphosphate 5-phosphatase

SLP65 Stable isotope labeling by amino acids in cell culture

SLP76 $\mathrm{SH} 2$ domain-containing leukocyte adaptor protein of $65 \mathrm{kDa}$ $\mathrm{Src}$ SH2 domain-containing leukocyte adaptor protein of $76 \mathrm{kDa}$ zusammengesetztes Akronym aus cellular und sarcoma

Syk spleen tyrosine kinase

TIRF total internal reflection fluorescence microscope T-Zell-Antigenrezeptor (und Plural)

XLA X-gekoppelte Agammaglobulinämie 


\section{Symbole für Aminosäuren}

$\begin{array}{ll}\text { Alanin } & \text { A } \\ \text { Arginin } & \text { R } \\ \text { Asparagin } & \text { N } \\ \text { Asparaginsäure } & \text { D } \\ \text { Cystein } & \text { C } \\ \text { Glutamin } & \text { Q } \\ \text { Glutaminsäure } & \text { E } \\ \text { Glycin } & \text { G } \\ \text { Histidin } & \text { H } \\ \text { Isoleucin } & \text { I } \\ \text { Leucin } & \text { L } \\ \text { Lysin } & \text { K } \\ \text { Methionin } & \text { M } \\ \text { Phenylalanin } & \text { F } \\ \text { Prolin } & \text { P } \\ \text { Serin } & \text { S } \\ \text { Threonin } & \text { T } \\ \text { Tryptophan } & \text { W } \\ \text { Tyrosin } & \text { Y } \\ \text { Valin } & \text { V }\end{array}$




\section{Einleitung}

Das Immunsystem mit seiner Vielfalt an Effektorzellen ermöglicht durch die Erkennung und Beseitigung von Pathogenen das Überleben des Organismus in seiner Umwelt. Dabei stellt die Immunantwort ein komplexes Zusammenspiel von verschiedenen Zelltypen und Mediatoren dar. Frühe, aber unspezifische Mechanismen, wie z.B. die Phagozytose von Pathogenen durch Makrophagen, werden dabei der angeborenen Immunität zugerechnet; spätere, aber spezifischere Reaktionen wie die Produktion von Antikörpern durch Plasmazellen sind Teil der adaptiven Immunabwehr.

Die Aktivierung der adaptiven Immunabwehr führt neben anderen Effekten zur Produktion spezifischer Antikörper. Diese Antikörper wurden erstmals 1890 von Behring und Kitasato als „Antitoxine“ beschrieben (von Behring und Kitasato 1890). Heute unterscheidet man zwei Formen von Antikörpern, nämlich eine membrangebundene und eine lösliche Form.

Eine regelrechte Differenzierung und Aktivierung von B-Zellen ist für eine funktionierende humorale Immunantwort essentiell. Membrangebundene Antikörper spielen als Teil der B- ZellAntigenrezeptoren (BZR) bei diesen Prozessen eine wichtige Rolle. Sie transduzieren nach erfolgreicher Antigenerkennung Signale, die in der B-Zelle Reaktionen wie Proliferation, Differenzierung oder auch den Umbau des Zytoskeletts im Rahmen der B-Zell-Aktivierung hervorrufen. Erst nach erfolgreicher Differenzierung von B-Zellen können lösliche Antikörper gebildet werden. Diese binden spezifisch an bestimmte Epitope eines Pathogens, welches dadurch opsoniert und inaktiviert wird. Zudem kann es durch die Antikörperbindung an Epitope der Pathogene zur Aktivierung des Komplementsystems kommen, was eine Rekrutierung von Phagozyten zur Folge hat, aber auch direkt zur Lyse und damit zur Eliminierung von Pathogenen führt (Tomlinson 1993).

In den letzten Jahren wurden große Fortschritte in der Erforschung der BZR-abhängigen Signalwege erzielt. In Teilen sind heute die molekularen Mechanismen, welche der B-Zell-Differenzierung und Aktivierung zugrunde liegen, verstanden. Bisher ist es jedoch nicht gelungen, diejenigen Proteine zu identifizieren, welche die Verknüpfung von proximalen und distalen Signalelementen der BZRSignaltransduktion darstellen. Mit der Identifizierung dieser bisher unbekannten Proteinkomplexe und der Erforschung von deren Regulation leistet meine Dissertation einen Beitrag zum Verständnis der Signalleitung durch den BZR und damit zur Funktionsweise von B-Zellen im Rahmen der adaptiven Immunantwort.

\subsection{Die B-Zell-Entwicklung: Vom prä-BZR zum Antikörper}

Eine selektive und spezifische Immunabwehr benötigt das Vorhandensein eines ausreichend großen BZell-Repertoires. Dafür ist eine regulierte Entwicklung und Proliferation der B-Zellen im Knochenmark eine wichtige Voraussetzung. 
Um eine regelrechte Entwicklung funktionstüchtiger B-Zellen zu gewährleisten und auszuschließen, dass die somatische Rekombination zur Ausbildung autoreaktiver Antigenrezeptoren führt, gibt es während der B-Zell-Entwicklung bestimmte Kontrollmechanismen. Diese umfassen u.a. die Oberflächenexpression und Signalleitung des prä-BZR und später des BZR als Voraussetzung für die weitere Entwicklung der B-Zellen. Nur die erfolgreiche Rekombination führt nämlich zur Expression von signalleitenden prä-BZR und BZR, durch welche Überlebenssignale vermittelt werden, die für das weitere Bestehen und die Reifung der Lymphozyten essentiell sind (Goodnow et al. 1995; Loffert et al. 1994). Auch das Überleben von reifen B-Zellen hängt von der regelrechten Expression und Funktion des BZR ab. So konnte gezeigt werden, dass die in-vivo-Deletion des BZR auf reifen BZellen zu deren Apoptose führt (Lam et al. 1997). Haben die B-Zellen diese kontrollierte Entwicklung schließlich erfolgreich durchlaufen, so folgt eine Überprüfung auf Selbst-Toleranz, bevor sie als IgM und IgD präsentierende, reife, aber noch naive B-Zellen das Knochenmark verlassen, um in das Lymphsystem zu gelangen. Dort werden sie durch die Interaktion mit Antigenen aktiviert und nehmen den Komplex aus BZR und gebundenem Antigen durch Endozytose auf. Peptide des Antigens werden daraufhin intrazellulär prozessiert und anschließend mittels MHC-II-Molekülen auf der Oberfläche der B-Zellen präsentiert, was eine Interaktion mit T-Helferzellen ermöglicht (Goodnow et al. 2010). Dies kann im Rahmen einer T-Zell abhängigen Immunantwort dazu führen, dass die B-Zellen proliferieren und dann entweder zu Plasmazellen differenzieren, welche Antikörper mit einer dem erkannten Epitop entsprechenden Spezifität freisetzen, oder aber zu langlebigen B-Gedächtniszellen (Goodnow et al. 1995). Diese haben wiederum die Fähigkeit, sehr schnell auf bereits vor langer Zeit erkannte Pathogene mit der Bildung von hochaffinen Antikörpern zu reagieren. Diese Prozesse werden als klonale Expansion und Selektion bezeichnet und wurden als Hauptprinzipien der adaptiven Immunabwehr bereits 1959 von M. Burnet beschrieben (Burnet 1959).

Nicht terminal differenzierte B-Zellen können sich zudem im Zuge einer Immunreaktion zu sog. „Germinal-center“-B-Zellen entwickeln, die in Lymphfollikeln proliferieren. Dabei kann es durch irreversible DNA-Rekombination zum Isotypenwechsel kommen, sodass anstelle von IgM auch IgG, IgA und IgE sekretiert werden, wobei jeder Isotyp durch bestimmte Eigenschaften seine präferentielle Funktion besitzt (Stavnezer et al. 2008). So wird IgM als erster Isotyp in einer humoralen Immunantwort freigesetzt, da für die Expression und Herstellung von IgM kein Isotypenwechsel notwendig ist. Diese Immunglobuline entstehen vor der somatischen Hypermutation und zeigen daher eine relativ niedrige Affinität zu ihren Antigenen, die aber durch die Ausbildung von Pentameren mit vielen Antigen-Bindungsstellen und einer dadurch erhöhten Avidität zum Teil kompensiert wird. IgG stellt den häufigsten Isotyp im Blut dar und dient hauptsächlich der Opsonierung und Komplementaktivierung, während $\operatorname{IgA}$ vornehmlich in sekretorischen Flüssigkeiten vorkommt und dort aufgrund der Abwesenheit von Phagozyten hauptsächlich Antigen neutralisierend wirkt. IgE führt in zellgebundener Form u.a. zur Mediatorfreisetzung aus Mastzellen (Deutsch und Fudenberg 1969; South et al. 1967). 
Zudem können „Germinal-center“-B-Zellen durch somatische Hypermutation ihrer variablen Immunglobulindomänen Immunglobuline höherer Affinität produzieren (Jacob et al. 1991). Das adaptive Immunsystem hat also nicht nur die Möglichkeit, spezifisch mit Immunglobulinen gegen Pathogene vorzugehen, sondern auch im Zuge der Immunreaktion durch Isotypenwechsel und somatische Hypermutation seine Effektivität zu erhöhen und letztlich durch die Ausbildung von Gedächtniszellen einen Schutz vor Reinfektion mit bereits bekannten Keimen aufzubauen.

Der BZR ist als Signalelement entscheidend für die regelgerechte Differenzierung der B- Zellen. Zudem transduziert er nach Erkennung von Fremdantigenen Signale, welche eine effektive humorale Immunantwort ermöglichen (Casellas et al. 2001; Reichlin et al. 2001).

\subsection{Die BZR-abhängige Signaltransduktion in aktivierten B-Zellen}

Der B-Zell-Antigenezeptor ist ein Multiproteinkomplex und besteht aus einem membrangebundenen Immunglobulin und einem nicht kovalent daran gebundenen invarianten Heterodimer bestehend aus Ig- $\alpha$ und Ig- $\beta$. Die nahezu unendliche Vielfalt an Antikörper-Spezifitäten, die für eine funktionierende Immunabwehr benötigt wird, wird erreicht durch somatische Rekombination von Gensegmenten, die für den variablen Anteil des Immunglobulins kodieren und erstmals von Susumu Tonegawa beschrieben wurden (Tonegawa 1983).

Das Heterodimer aus Ig- $\alpha$ und Ig- $\beta$ ist evolutionär hochkonserviert und beide Ketten verfügen jeweils über eine extrazelluläre Ig-Domäne, eine transmembrane $\alpha$ - Helix und einen das „Immunoreceptor tyrosine-based activation motif" (ITAM) enthaltenden zytoplasmatischen Anteil. Eine wichtige Funktion dieses Heterodimers ist die Abschirmung polarer Aminosäurereste der mIgMTransmembrandomäne, welche erst eine Oberflächenexpression von IgM ermöglicht. Die einzelnen Komponenten des BZR können also nicht unabhängig voneinander auf der Zelloberfläche exprimiert werden (Wienands 2000). Zudem werden Ig- $\alpha$ und Ig- $\beta$ für die Signaltransduktion benötigt.

Das intrazelluläre ITAM weist die Aminosäurekonsensussequenz D/E $x_{7} D / E x_{2} \mathrm{Y} \mathrm{x}_{2} \mathrm{I} / \mathrm{L} \mathrm{x}_{7} \mathrm{Y} \mathrm{x}_{2} \mathrm{I} / \mathrm{L}$ auf und kommt jeweils einmal in Ig- $\alpha$ und Ig- $\beta$ vor (Reth 1989). Dieses Motiv konnte als das kleinste für die Signaltransduktion des BZR notwendige Segment identifiziert werden. Dazu wurde die Signalleitung chimärer Proteine, die als zytoplasmatische Domäne die intrazellulären Anteile von Ig- $\alpha$ und Ig- $\beta$ enthielten, untersucht; nach Quervernetzung dieser ITAM aufweisenden Chimären wurden ähnliche intrazelluläre Reaktionen hervorgerufen wie nach Antigen-abhängiger BZR-Stimulation (Flaswinkel und Reth 1994; Kim et al. 1993; Sanchez et al. 1993).

Die Bindung von oligomeren oder multivalenten Antigenen an das membrangebundene Immunglobulin des BZR ist der Auslöser einer Vielzahl von Signalkaskaden, die u.a. im Zellkern für eine Veränderung des Gentranskriptionsmusters sorgen und somit eine biologische Reaktion der B-Zellen auf die Antigenbindung hervorrufen. Durch die Bindung solcher Antigene kommt es zur 
Quervernetzung der BZR, welche dadurch in räumliche Nähe zueinander gelangen (Sohn et al. 2006). Zudem lokalisieren sich die BZR nach Antigenbindung in sog. „Lipid-Rafts“, welche Signalplattformen der Zellmembran darstellen und sich u.a. durch die Anreicherung von Phospholipiden und bestimmten Proteinen wie Kinasen der Src-Familie auszeichnen. „Lipid-Rafts“ sind dynamische Strukturen, die Proteine aufnehmen oder ausschließen können, wobei sie auf diese Weise eine für die Signalleitung wichtige Kolokalisation von Signalelementen ermöglichen (Cheng et al. 1999).

Protein-Tyrosin-Kinasen der Src-Familie wie Lyn, Blk und Fyn zeigen bereits eine schwache Assoziation mit unphosphorylierten ITAMs der BZR. Gelangen diese nun aufgrund der Antigenbindung in räumliche Nähe zueinander, dann phosphorylieren und aktivieren sich die SrcKinasen gegenseitig, um dann wiederum die Tyrosine der ITAMs zu phosphorylieren. Über diese phosphorylierten ITAMs wird dann die Kinase Syk („spleen tyrosine kinase“) zum BZR an die Zellmembran rekrutiert. Dort wird Syk durch Src-Kinasen und auch durch Autophosphorylierung aktiviert und phosphoryliert anschließend neben den ITAMs zahlreiche Signalproteine wie auch SLP65 („SH2 domain-containing leukocyte adaptor protein of $65 \mathrm{kDa}$ “, auch BLNK oder BASH genannt) (Fu et al. 1998; Goitsuka et al. 1998; Wienands et al. 1996).

SLP65, das zur Gruppe der Adapterproteine gehört, also keine intrinsische enzymatische Aktivität besitzt, bildet durch Bindung von verschiedenen Proteinen den Kern eines Multiproteinkomplexes, der für die weitere Signalleitung in B-Zellen unabdingbar ist. Die Kinase Syk phosphoryliert SLP65 an verschiedenen Tyrosinresten. Die Folge ist, dass zum einen PLC- $\gamma 2$ („Phospholipase C- $\gamma 2$ “) und zum anderen Btk (Bruton's Tyrosin-Kinase) jeweils mittels ihrer SH2-Domänen an die Phosphotyrosine von SLP65 binden, was dann zur Aktivierung von PLC- $\gamma 2$ durch Syk und Btk führt; die genannten Signalproteine bilden zusammen den sog. $\mathrm{Ca}^{2+}$-Initiationskomplex (Chiu et al. 2002). Im Zuge der BZR-Stimulation gelangt PLC- $\gamma 2$ durch Membranrekrutierung von SLP65 zur Zellmembran, wobei der Mechanismus dieser stimulationsabhängigen Membranrekrutierung bisher noch nicht hinreichend aufgeklärt werden konnte (s. Kapitel 1.4) (Koretzky et al. 2006). In der Zellmembran befindet sich das Substrat von PLC- $\gamma 2$, nämlich Phosphatidylinositol-4,5-bisphosphat ( $\left.\mathrm{PIP}_{2}\right)$, welches in einer enzymatischen Reaktion zu Inositol-1,4,5-triphosphat $\left(\mathrm{IP}_{3}\right)$ und Diacylglycerol (DAG) umgesetzt wird. $\mathrm{IP}_{3}$ führt über die Bindung an $\mathrm{IP}_{3}$-Rezeptoren des endoplasmatischen Retikulums zur Freisetzung von intrazellulärem $\mathrm{Ca}^{2+}$ (Leo et al. 2002), was letztlich einen Einstrom von extrazellulärem $\mathrm{Ca}^{2+}$ und somit einen deutlichen Anstieg der intrazellulären $\mathrm{Ca}^{2+}$-Konzentration zur Folge hat (Rao und Hogan 2009). Dieser erhöhte Spiegel von intrazellulärem $\mathrm{Ca}^{2+}$ hat eine maßgebliche Funktion für den weiteren Signalleitungsprozess, da verschiedene Proteine durch $\mathrm{Ca}^{2+}$-Ionen reguliert werden (Engelke et al. 2007).

So wird zum Beispiel durch den Komplex aus $\mathrm{Ca}^{2+}$ und Calmodulin die Serin/Threonin-Phosphatase Calcineurin aktiviert, die daraufhin wiederum den im Zytoplasma vorliegenden Transkriptionsfaktor NFAT („Nuclear factor of activated T-cells“) dephosphoryliert. Dieser kann anschließend mittels 
seiner Kernlokalisierungsequenz in den Zellkern translozieren und dort letztlich die Genexpression regulieren (Rao 2009).

Auch NFKB (,nuclear factor kappa-light-chain-enhancer of activated B cells“), ebenfalls ein zentraler Transkriptionsfaktor, beeinflusst das Genexpressionsmuster, nachdem er durch PKC (,protein kinase C“) aktiviert worden ist. Um NFאB aktivieren zu können, muss PKC selbst in ihre aktive Form überführt werden, was durch DAG und $\mathrm{Ca}^{2+}$, die Produkte der von PLC- $\gamma 2$ katalysierten Reaktion, geschieht. Damit ist auch die Aktivierung von NFkB abhängig von der durch Antigene vermittelten Stimulation des BZR (Ruland und Mak 2003b).

Neben diesen letztlich durch $\mathrm{Ca}^{2+}$ und DAG regulierten Signalwegen gibt es weitere Signalkaskaden, die nach Stimulation des BZR zur Transkriptionsregulation beitragen. Dazu gehören u.a. MAP-Kinase (,mitogen-activated protein kinases“) -Kaskaden, die in vielen Zellen eine wichtige Funktion in der Regulation der Transkription, der Apoptose und des Zellzyklus übernehmen. In der vom BZR vermittelten Signalleitung spielen verschiedene MAP-Kinasen eine Rolle; zu diesen zählen insbesondere die MAP-Kinasen Erk (,extracellular signal regulated kinase“), p38 und JNK (,c- Jun Nterminal kinase"), welche in B-Zellen an der Regulation der Genexpression durch den Transkriptionsfaktor AP-1 beteiligt sind (Foletta et al. 1998). Ap-1 und auch der Komplex aus NFAT und AP-1 tragen wesentlich zur Kontrolle des Zellzyklus, der Aktivierung und der Differenzierung von B-Zellen bei (Foletta et al. 1998).

Unterschiedliche Signalwege führen nach Stimulation des BZR zu einem Umbau des Zytoskeletts, wodurch in erster Linie eine effektive Erkennung und Aufnahme von Antigenen ermöglicht wird. Im Zuge dieses Prozesses kommt es dann zu einer fein regulierten Aktivierung zentraler Transkriptionsfaktoren wie NFAT, NFאB und AP-1, die durch differentielle Genregulation schließlich eine Differenzierung sowie eine effektive Immunantwort durch B-Zellen ermöglichen (Ruland und Mak 2003a). 


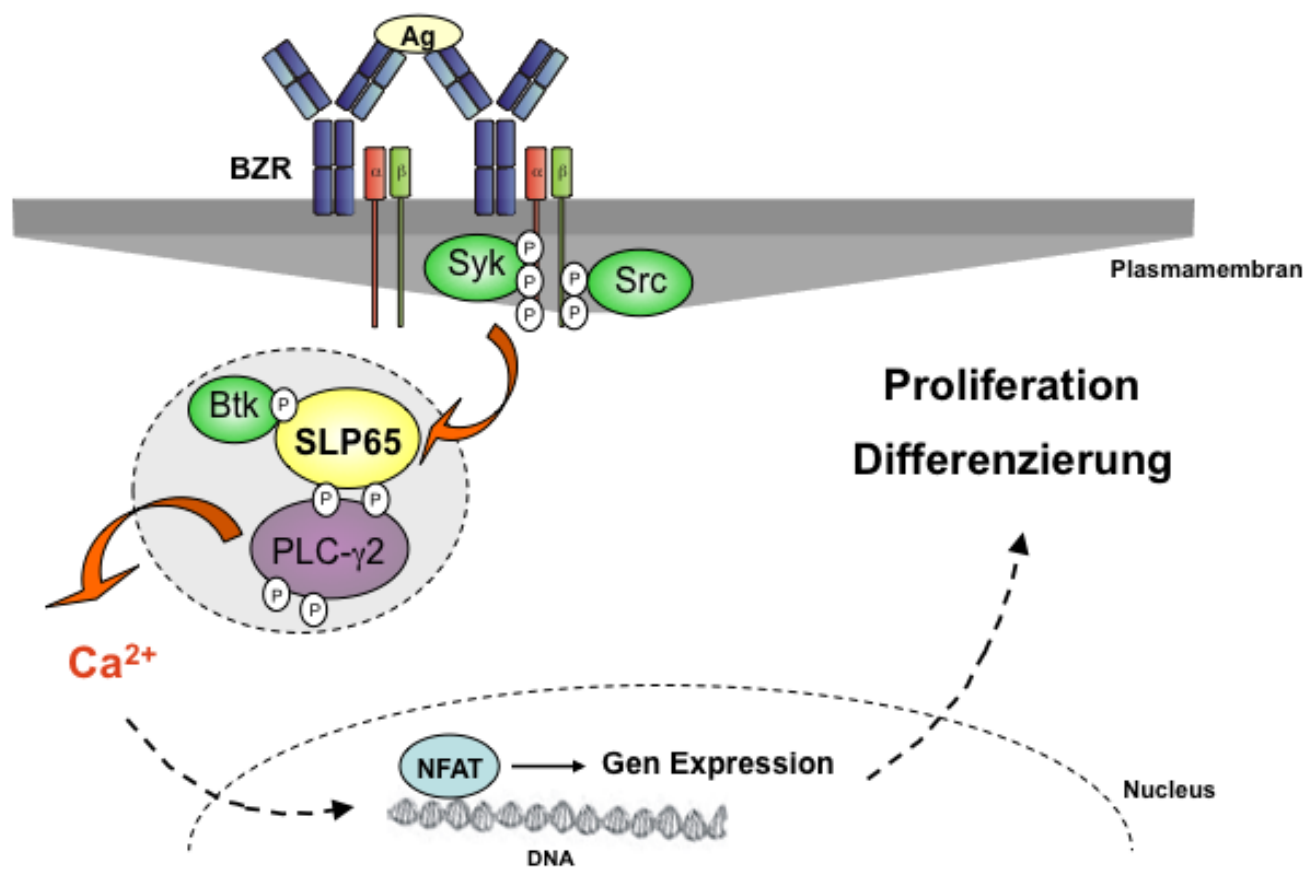

\section{Abb.1: Signaltransduktion durch den BZR}

Die vereinfachte Darstellung zeigt die wichtigsten Effektorproteine des $\mathrm{Ca}^{2+}$-Signalwegs in aktivierten B-Zellen. Das Adapterprotein SLP65 wird im Zuge der BZR-Stimulation durch die Tyrosinkinase Syk phosphoryliert und bildet anschließend den Kern des sog. Calciuminitiationskomplexes. Die Freisetzung von $\mathrm{Ca}^{2+}$ führt u.a. zur Regulation der Transkription durch den Transkriptionsfaktor NFAT.

\subsection{Die Rolle und Funktion von Adapterproteinen in der intrazellulären Signalleitung}

Rezeptoren wie BZR und TZR transduzieren Signale, die nach Weiterleitung und Amplifikation im Inneren der Zelle Effekte wie Aktivierung, Proliferation, Differenzierung oder auch Apoptose auslösen können. Zur Erzeugung dieser unterschiedlichen, teils sogar gegensätzlichen Reaktionen reicht allerdings die einfache intrazelluläre Signalleitung nicht aus; vielmehr müssen die Signale in ihrer Kinetik und Intensität fein reguliert werden, wodurch dann differentielle Reaktionen der Zelle auf extrazelluläre Reize erst möglich werden.

Sowohl bei der Signalleitung als auch bei deren Regulation und Integration spielen Adapterproteine eine zentrale Rolle. Sie haben zwar keine intrinsische enzymatische Aktivität, dafür können sie mittels bestimmter Bindungsmotive und Domänen eine Vielzahl von Signalproteinen assemblieren, wodurch 
diese in räumliche Nähe zueinander gelangen und auf diese Weise in ihrer Aktivität reguliert werden können (Pawson 2007). So gewährleisten Adapterproteine die Kolokalisation von Signalproteinen, welche für eine funktionierende Signaltransduktion und deren Regulation notwendig ist. Zudem sorgen sie oft auch für die regelrechte subzelluläre Lokalisation von Signalkomplexen, indem sie mit anderen Proteinen oder Bestandteilen der Zellmembran interagieren und dadurch an bestimmte Orte in der Zelle wie z.B. „Lipid-Rafts“ rekrutiert werden. Oft gelangen erst auf diese Weise Enzyme im Signalkomplex in die Nähe ihrer Substrate, die daraufhin umgesetzt werden und deren Produkte als „Second Messenger “ Signale vermitteln (Pawson 2007; Rudd 1999).

Es gibt verschiedene Proteininteraktionsdomänen, die entweder konstitutive oder stimulationsabhängige Protein-Protein-Interaktionen ermöglichen und daher für eine regulierte Signaltransduktion notwendig sind. Oftmals finden sich solche Domänen in Adapterproteinen. So binden SH2 (,src-homology 2“)- und PTB (,Phosphotyrosine-binding“)-Domänen an Phosphotyrosinmotive. SH2-Domänen können außerdem eine regulatorische Funktion ausüben, indem die Bindung von Phosphotyrosinmotiven zu einer Konformationsänderung führt, wodurch wiederum u.a. die Aktivität von Kinasen beeinflusst werden kann. Neben SH2-Domänen gibt es SH3 (,srchomology 3“)-Domänen, welche an prolinreiche Sequenzen binden, was konstitutive Proteininteraktionen zur Folge hat (Pawson et al. 2002).

\subsection{Die SLP-Familie: Zentrale Adapterproteine in der BZR- und TZR-vermittelten Signalleitung}

Zur SLP-Familie der Adapterproteine gehören SLP65, SLP76 und Clnk („Cytokine-dependent hematopoetic cell linker"), welche in verschiedenen hämatopoetischen Zellen exprimiert werden und eine Schlüsselrolle in der von ITAMs ausgehenden Signalleitung einnehmen (Koretzky et al. 2006) . Die Mitglieder der SLP-Familie verbindet eine ausgeprägte Strukturhomologie; alle verfügen über eine saure N-terminale Region mit Tyrosinphosphorylierungsmotiven, eine zentrale prolinreiche Region und eine C-terminale SH2-Domäne, wodurch letztlich zahlreiche Proteininteraktionen ermöglicht werden. SLP65 verfügt zudem über eine N-terminale basische Effektor-Domäne, welche einen putativen „Leucine-Zipper“ darstellt (Kohler et al. 2005). Die wichtigsten bisher bekannten Interaktionspartner der SLP-Familie sind in Abbildung 2 dargestellt. 

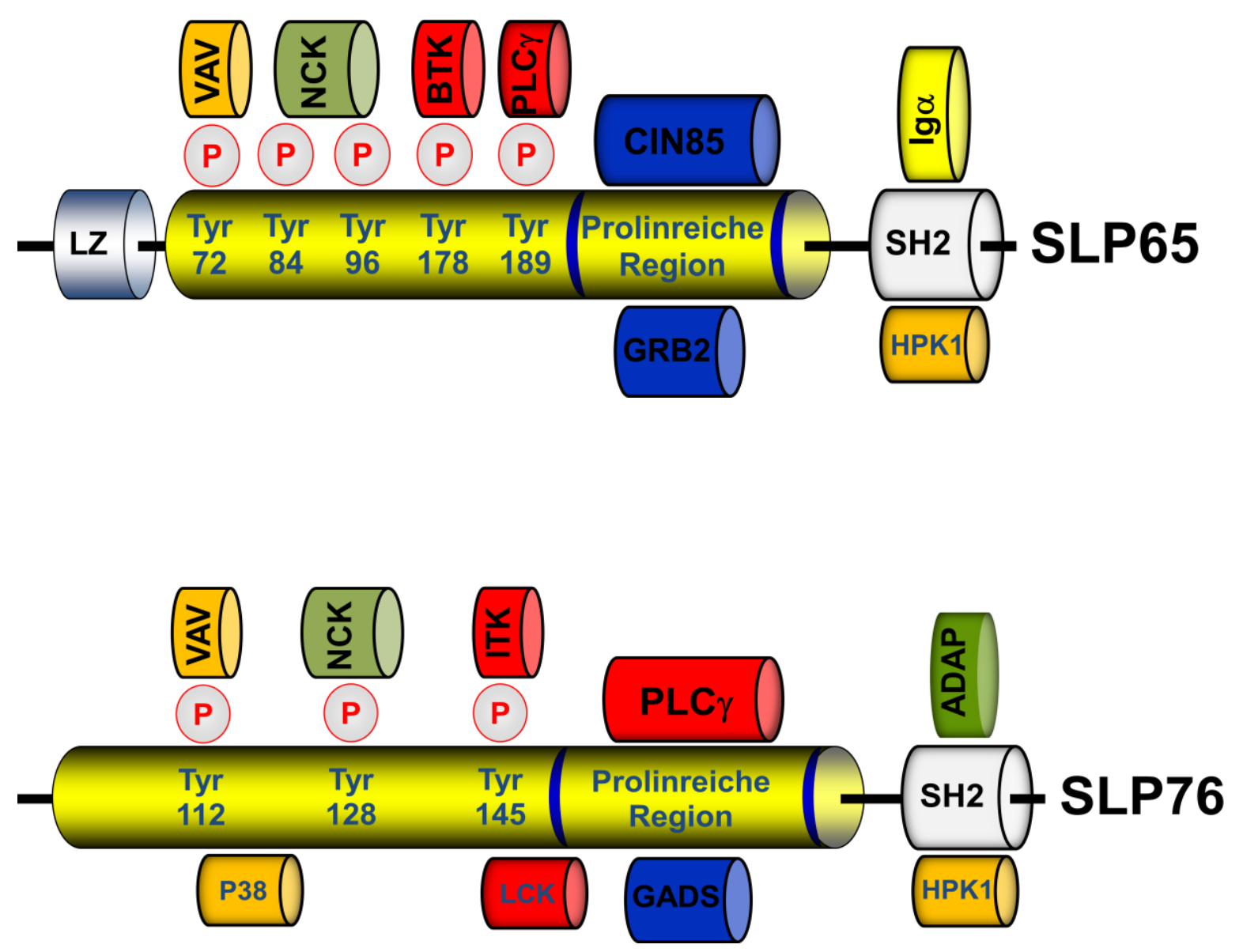

Abb. 2: Domänen-Struktur und Interaktionspartner von Proteinen der SLP-Familie

LZ steht für „Leucine-Zipper“, SH2 für „,src-homology 2“ -Domäne. Orange unterlegt sind Proteine der MAPKinasen-Signalleitung; rot sind diejenigen Proteine, die für die $\mathrm{Ca}^{2+}$-Freisetzung verantwortlich sind. Grün markiert sind Zytoskelett-Regulatoren. In Blau sind Adapterproteine dargestellt. Ig $\alpha$ stellt einen Teil des BZR dar und ist gelb unterlegt.

SLP65 wurde als Substrat von Protein-Tyrosin-Kinasen nach BZR-Stimulation bereits 1998 identifiziert und konnte außer in B-Zellen auch in Makrophagen nachgewiesen werden. In der durch den BZR vermittelten Signalleitung ist SLP65 der zentrale Adapter, der zum einen die Brücke zwischen proximalen und distalen Signalelementen bildet und zum anderen durch deren Kolokalisation eine Regulation der Aktivität dieser Proteine ermöglicht (Wienands et al. 1998; Fu et al. 1998; Goitsuka et al. 1998).

Mit Hilfe SLP65-defizienter DT40 B-Zellen konnte gezeigt werden, dass SLP65 sowohl für die stimulationsabhängige Phosphorylierung von PLC- $\gamma 2$ und damit die $\mathrm{Ca}^{2+}$-Mobilisierung als auch für die Aktivierung der MAP-Kinasen Erk, p38 und JNK notwendig ist (Ishiai et al. 1999). In weiteren Studien wurde die Funktion der 5 teils evolutionär hochkonservierten Phosphotyrosinmotive von SLP65 in diesen Signalwegen untersucht und die präferentiellen Bindungspartner dieser Motive identifiziert. Demnach binden Vav und Nck vornehmlich an das Motiv $\mathrm{pY}_{72} \mathrm{ENP}$, Btk an $\mathrm{pY}_{96} \mathrm{EPP}$ und 
PLC- $\gamma 2$ an $\mathrm{pY}_{84} \mathrm{VVP}, \mathrm{pY}_{178} \mathrm{IVP}$ und $\mathrm{pY}_{189} \mathrm{IEP}$. Die Rekonstitution der SLP65-defizienten DT40 BZellen mit der Y5F-Mutante, bei der die 5 für die Signalleitung entscheidenden Tyrosine gegen Phenylalanine ausgetauscht wurden, löst keine $\mathrm{Ca}^{2+}$-Freisetzung mehr aus; des Weiteren wird die p38Aktivierung vollständig, die von JNK und Erk zumindest teilweise inhibiert (Chiu et al. 2002).

Mittels SLP65-defizienten Mäusen konnte gezeigt werden, dass das Adapterprotein nicht nur für die B-Zell-Aktivierung notwendig ist, sondern in vivo auch für die Entwicklung und Differenzierung dieser Zellen. Die SLP65-defizienten Zellen zeigen einen partiellen Entwicklungsarrest im Stadium der großen prä-B-Zellen (Jumaa et al. 1999; Minegishi et al. 1999; Pappu et al. 1999); im Menschen konnte die SLP65-Defizienz bzw. verminderte SLP65-Expression in B-Zellen als eine Ursache für die Entstehung von akuten lymphatischen Leukämien (ALL) nachgewiesen werden (Jumaa et al. 2003). Damit kommt dem Adapterprotein die Funktion eines Tumorsuppressors zu; zum einen limitiert es nämlich die B-Zell-Proliferation und zum anderen induziert es die B-Zell-Differenzierung. Als molekulare Grundlage dieser Funktion konnte kürzlich der Prä-BZR-abhängige PI3Kinase/Proteinkinase-B/Foxo-Signalweg in Prä-B-Zellen identifiziert werden (Herzog et al. 2009).

Auch für die Entstehung der X-gekoppelten Agammaglobulinämie sind neben Mutationen im Gen für die Bruton's Tyrosin-Kinase (Btk) Mutationen im slp65-Gen verantwortlich (Xu et al. 2000). Bei der Agammaglobulinämie handelt es sich um einen angeborenen Immundefekt. Es kommt dabei zu einem Mangel aller Immunglobulinklassen durch einen Entwicklungsarrest zwischen den Stadien der prä-BZellen und den reifen CD19+-B-Zellen, welche in der Peripherie nahezu fehlen. Betroffene Kinder zeigen eine Neigung zu vorwiegend bakteriellen Infektionen; eine kausale Therapiemöglichkeit gibt es bisher nicht, jedoch kann die Lebenserwartung betroffener Kinder durch die Gabe von Immunglobulinen und einer konsequenten antibiotischen Therapie von Infekten deutlich verbessert werden. Eine aberrante SLP65-Funktion kann also zu schwerwiegenden Funktionsdefiziten von BZellen führen, was zum einen in Leukämien oder aber auch in angeborenen Immundefekten resultieren kann (Jumaa et al. 2003; Xu et al. 2000). Diese Beispiele unterstreichen die Schlüsselrolle von SLP65 für die BZR-abhängige Signalleitung und damit für die regelrechte Funktion der B-Zellen im Organismus.

Zur Ausführung seiner Funktion muss SLP65 in die Nähe der aktivierten BZR gelangen, um dort durch Syk phosphoryliert zu werden. Erst an der Zellmembran kann dann der durch SLP65 gebildete $\mathrm{Ca}^{2+}$-Initiationskomplex wirken. Der molekulare Mechanismus der Membranrekrutierung von SLP65 konnte bisher nicht aufgeklärt werden. In T-Zellen sorgt das Transmembranprotein „Linker of activated T-cells“ (LAT) für die Membranlokalisierung von SLP76. Ein LAT ähnliches Protein, das in B-Zellen exprimiert wird und die SLP65-Membranrekrutierung vermittelt, konnte bisher nicht identifiziert werden. Wichtig für die Membranrekrutierung des Adapterproteins scheinen seine Nterminale basische Effektor-Domäne und die C-terminale SH2-Domäne zu sein (Abudula et al. 2007; Engels et al. 2001; Kohler et al. 2005). Allerdings konnten bisher keine essentiellen Liganden identifiziert werden, die die SLP65-Relokalisation über diese Domänen vermitteln. Das non-ITAM- 
Phosphotyrosin 204 in Ig-alpha bindet zwar die SLP65-SH2-Domäne, hat allerdings nur einen verstärkenden Effekt auf die SLP65-Rekrutierung (Patterson et al. 2006).

SLP65 reguliert auch $\mathrm{Ca}^{2+}$-unabhängige Signalwege; ein Beispiel dafür ist die Regulation der MAPKinasen p38 und JNK durch SLP65, welche unabhängig von der Tyrosinphosphorylierung ist, und daher durch andere Mechanismen gesteuert werden muss (Grabbe und Wienands 2006; Ishiai et al. 1999). Allein die Tatsache, dass SLP65 sowohl für die Entwicklung der B-Zellen als auch später für deren Aktivierung verantwortlich ist, legt die Vermutung nahe, dass es neben der Tyrosinphosphorylierung weitere komplexe Regulationsmechanismen gibt. Erst eine solche Signalregulation würde die verschiedenen biologischen Reaktionen der B-Zellen im Zuge der durch SLP65 vermittelten Signalleitung erklären. Eine weitere Möglichkeit der Proteinregulation könnte die Phosphorylierung von SLP65 an Serin- bzw. Threoninresten darstellen. In großen Phosphoproteomstudien in HELA Zellen konnte passend zu dieser Hypothese gezeigt werden, dass Serin- bzw. Threonin-Phosphorylierung über 95\% der gesamten Proteinphosphorylierung ausmachen (Olsen et al. 2006). Zudem ergaben sich in HELA Zellen differentielle Phosporylierungskinetiken für die unterschiedlichen Phosphorylierungsstellen in Abhängigkeit von der „epidermal-growth-factorreceptor" (EGFR) -Stimulation (Olsen et al. 2006). Eine komplexe Phosphorylierung von SLP65 in BZellen wäre also durchaus vorstellbar und könnte u.a. weitere bisher unbekannte SLP65-mediierte Proteininteraktionen vermitteln; das bisher bekannte „SLP65-Interaktom“ kann nämlich die Funktionsweise des Adapterproteins nicht hinreichend erklären. Insbesondere bleibt die Schlüsselfrage, nämlich auf welche Weise SLP65 zur Zellmembran bzw. dem Komplex bestehend aus dem BZR und Syk rekrutiert wird, ungeklärt.

\section{Funktionelle Proteomics und BZR-vermittelte Signaltransduktion}

Die Massenspektrometrie ist eine Technologie, welche die Bestimmung von Molekülmassen freier Ionen im Hochvakuum ermöglicht. Diese Technologie kann zur Proteinanalytik eingesetzt werden. Proteine werden dabei enzymatisch zu Peptiden verdaut, welche dann in der Ionenquelle eines Massenspektrometers ionisiert werden. Mittels Massenanalysator und Detektor können für die entsprechenden ionisierten Peptide und deren Fragment-Ionen das Masse-zu-Ladungs-Verhältnis (m/z) bestimmt werden. Der Abgleich des für ein Peptid bestimmten $\mathrm{m} / \mathrm{z}$-Werts und der theoretischen Peptid-Masse, welche sich aufgrund der bekannten Genom- bzw. Aminosäuresequenz berechnen lässt, ermöglicht schließlich die Identifizierung eines Proteins.

In den letzten Jahren gab es große technische Fortschritte auf dem Gebiet der Massenspektrometriebasierten Proteinanalytik. Das Vorhandensein der gesamten humanen Genomsequenz und die Verbesserung der Genauigkeit und Sensitivität der Massenspektrometer erlauben heute die Analyse komplexer Proteome. Dabei ist nicht nur die reine Proteinidentifikation möglich, sondern auch der 
Nachweis post-translationaler Modifikationen wie z.B. der Protein-Phosphorylierung an Tyrosin-, Threonin- und Serinresten (Olsen et al. 2006). Zudem gibt es inzwischen die Möglichkeit der relativen und auch absoluten Quantifizierung von Proteinen. D.h., dass neben qualitativen auch quantitative Analysen von Proteinen und deren Modifikationen möglich sind (Blagoev et al. 2004; Ong et al. 2002).

Die intrazelluläre Signalleitung wird maßgeblich durch post-translationale Protein-Modifikationen und fein regulierte Protein-Protein-Interaktionen gesteuert. Zur Untersuchung der SLP65-Funktionsweise habe ich in meiner Doktorarbeit Verfahren etabliert, die eine effektive Aufreinigung von Proteinen und deren Interaktionspartnern ermöglichen, die dann wiederum massenspektrometrisch analysiert werden können. Somit habe ich sowohl das Phosphorylierungsmuster von SLP65 als auch dessen Interaktom, d.h. die Komponenten des SLP65-Komplexes, bestimmen können. In funktionellen zellbiologischen Studien konnte ich des Weiteren, basierend auf den gewonnenen Daten, den bisher unbekannten Membranrekrutierungsmechanismus von SLP65 und den Einfluss der SLP65Serinphosphorylierung auf die BZR-vermittelte Signalleitung aufklären.

Mittels der im Folgenden beschriebenen Verfahren gelang es ebenfalls, die von dem Adapterpotein Grb2 und der Tyrosin-Kinase Syk gebildeten Multiproteinkomplexe zu charakterisieren.

Zur Untersuchung von SLP65 habe ich in einem ersten Schritt SLP65-defiziente DT40-B-Zellen mit SLP65 rekonstituiert, welches am N-Terminus eine Peptid-Markierung, den sog. ONE-STREP-Tag beinhaltet (s. Fig.1, Oellerich et al. 2009, P.1741). Dieser Tag war anderen Tags, wie z.B. dem Flagoder HA-Tag, im Hinblick auf die Aufreinigungseffizienz bei Testversuchen überlegen. Nach Lyse der rekonstituierten DT40-Zellen konnte ich mittels einer sog. Streptactin-Matrix ONE-STREP-SLP65 einschließlich der interagierenden Proteine aufreinigen und nach SDS-Gelelektrophorese die aufgereinigten Proteine mittels Coomassie-Färbung sichtbar machen (s. Abb. 3). 

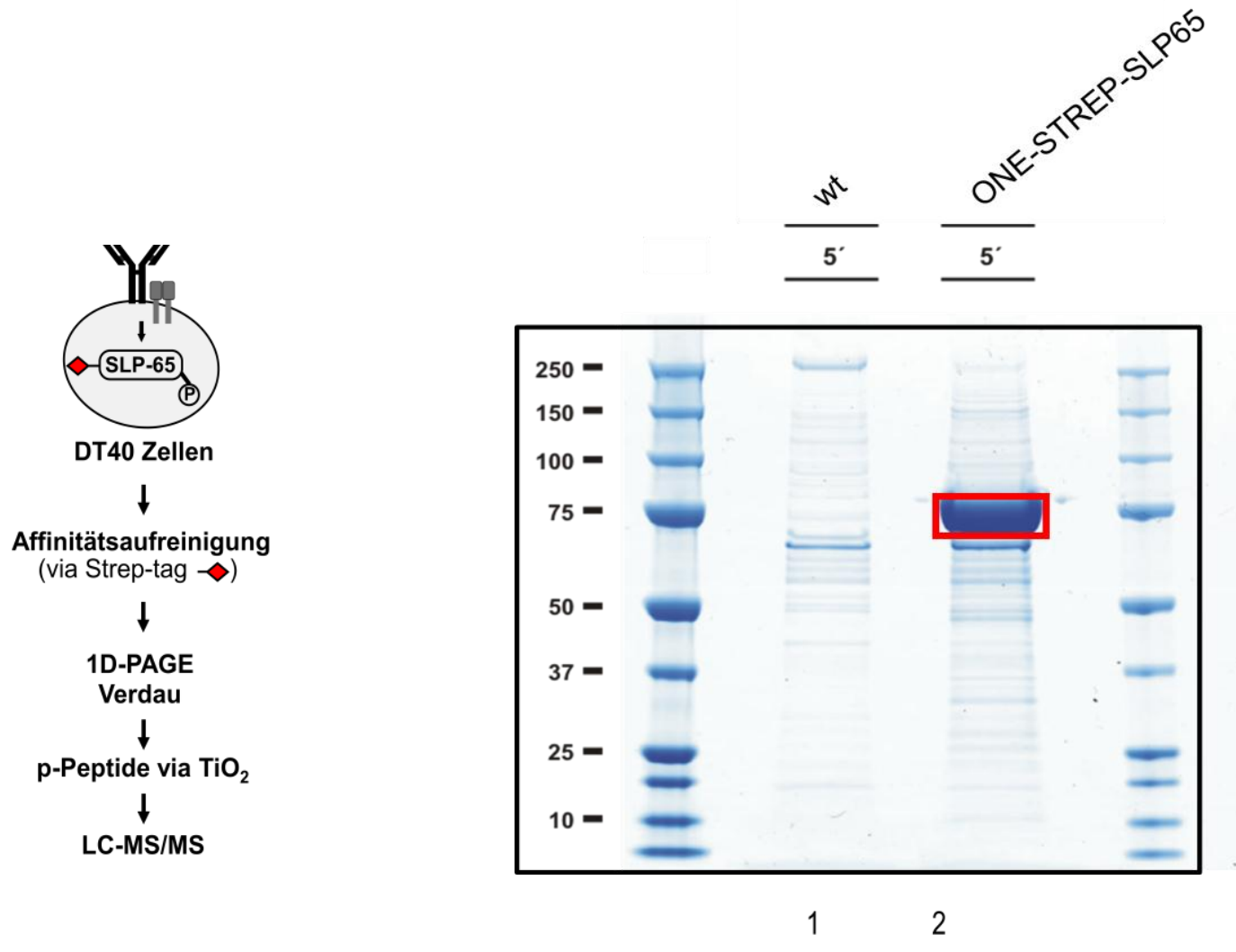

\section{Abb. 3: Experimenteller Ablauf und Coomassie-gefärbtes SDS-Gel}

Nach Streptactin-basierter Affinitätspräzipitation wurden die eluierten und denaturierten Proteine mittels 1DGelelektrophorese aufgetrennt und anschließend mittels kolloidaler Coomassie-Lösung angefärbt. Spur 1 (wt) enthält die Proteine aus wildtypischen DT40-Zellen (Negativkontrolle). Spur 2 (ONE-STREP-SLP65) diejenigen Proteine aus den Zellen, die ONE-STREP-getaggtes SLP65 exprimieren. Die SLP65 enthaltende Bande ist rot umrandet.

An den Seiten befindet sich der Proteinmarker mit den entsprechenden molekularen Massen (kDa).

Die SLP65 enthaltende Bande wurde ausgeschnitten und nach tryptischem Verdau wurden die phosphorylierten Peptide mittels Titaniumdioxid angereichert. Diese Peptide wurden anschließend massenspektrometrisch untersucht.

\subsection{Analyse der SLP65-Phosphorylierung}

Zur Bestimmung von Phosphorylierungsstellen in SLP65 wurde SLP65 aus unstimulierten und BZRstimulierten DT40-Zellen aufgereinigt und das gewonnene Eluat im SDS-Gel aufgetrennt. Nach Coomassie-Färbung wurde die SLP65 beinhaltende Bande (s. Abb. 3) ausgeschnitten und das Protein mittels Trypsin (oder Chymotrypsin) verdaut. Die dadurch gewonnenen Phospho-Peptide wurden dann mittels einer Titaniumdioxid-Matrix angereichert und anschließend massenspektrometrisch mit einem LTQ-Orbitrap-XL-Hybrid-Massenspektrometer analysiert. Bei der Phosphorylierungsanalytik ist die 
Titaniumdioxid-basierte Anreicherung der Phospho-Peptide ein essentieller Schritt, da sonst die unphosphorylierten Peptide in der zu messenden Probe überwiegen und daher vornehmlich analysiert werden (Larsen et al. 2005). Die schematische Dastellung des Experimentablaufs ist in Abbildung 4 (s. auch Fig. 2A, Oellerich et al. 2009, P.1742) dargestellt.

Anhand der b- bzw. y- Ionen-Serien können nach der Messung, die sowohl im MS- als auch MSMSModus abläuft, einzelne Phosphorylierungsstellen nachgewiesen werden. Dabei wird im MS-Modus der Quotient aus Masse und Ladung $(\mathrm{m} / \mathrm{z})$ des ionisierten tryptischen Peptids bestimmt. Für ein einfach phosphoryliertes Peptid bedeutet das im Vergleich zu der unphosphorylierten Form einen Massenzuwachs von 80 a.m.u. (,atomic mass units"), der durch die Phospho-Gruppe bedingt ist; dabei bleibt allerdings unklar, welche Aminosäure des Peptids phosphoryliert ist. Im MSMS-Modus wird daher das zu analysierende Peptid in einer Kollisionskammer fragmentiert und m/z für die einzelnen Fragmentionen bestimmt. Dies ergibt dann für ein bestimmtes ionisiertes Peptid die sog. b- bzw. yIonen-Serien. Aus diesen Informationen lassen sich nun oftmals die genaue Position der Phosphorylierung bestimmen. Serin- bzw. Threonin-Phosphorylierung zeigt nach Fragmentierung einen Massenverlust von 98 a.m.u., der durch den Verlust von Phosphorsäure bedingt ist; Tyrosinphosphorylierung zeigt nach Fragmentierung hingegen weiterhin einen Massenzuwachs von 80 a.m.u. (s. Fig. 2B, Oellerich et al. 2009, P.1742). Im Bezug auf SLP65 konnten mittels der beschriebenen Methode 41 Phosphorylierungsstellen bestimmt werden, wovon 35 bisher unbekannt waren (s. Fig. 3, Oellerich et al. 2009, P.1742). Damit gehört SLP65 zu einem der meist phosphorylierten Adapterproteine; eine starke Regulierung seiner Funktion durch reversible Phosphorylierung liegt demnach nahe.

\subsection{Relative Quantifizierung von Phosphopeptiden mittels SILAC}

SILAC bedeutet Stable Isotope Labeling by Amino acids in Cell Culture und ist eine Methode, die in Kombination mit Massenspektrometrie die relative Quantifizierung von Peptiden und Proteinen ermöglicht (Ong et al. 2002). Dabei werden Zellen wie z.B. DT40-Zellen in Nährmedium kultiviert, das Arginin und Lysin mit definierten Massen enthält. Neben der Kombination von natürlichem Arginin (R=174.2 g/mol) und Lysin $(\mathrm{K}=146.19 \mathrm{~g} / \mathrm{mol})$ gibt es z.B. Arginin, das 6 a.m.u., und Lysin, das 4 a.m.u. schwerer ist. Die Massenunterschiede sind dadurch bedingt, dass in den Aminosäuren eine definierte Anzahl von schwereren Kohlenstoff- bzw. Stickstoff- oder Wasserstoff- Isotopen vorliegen (s. Abb. 4). 

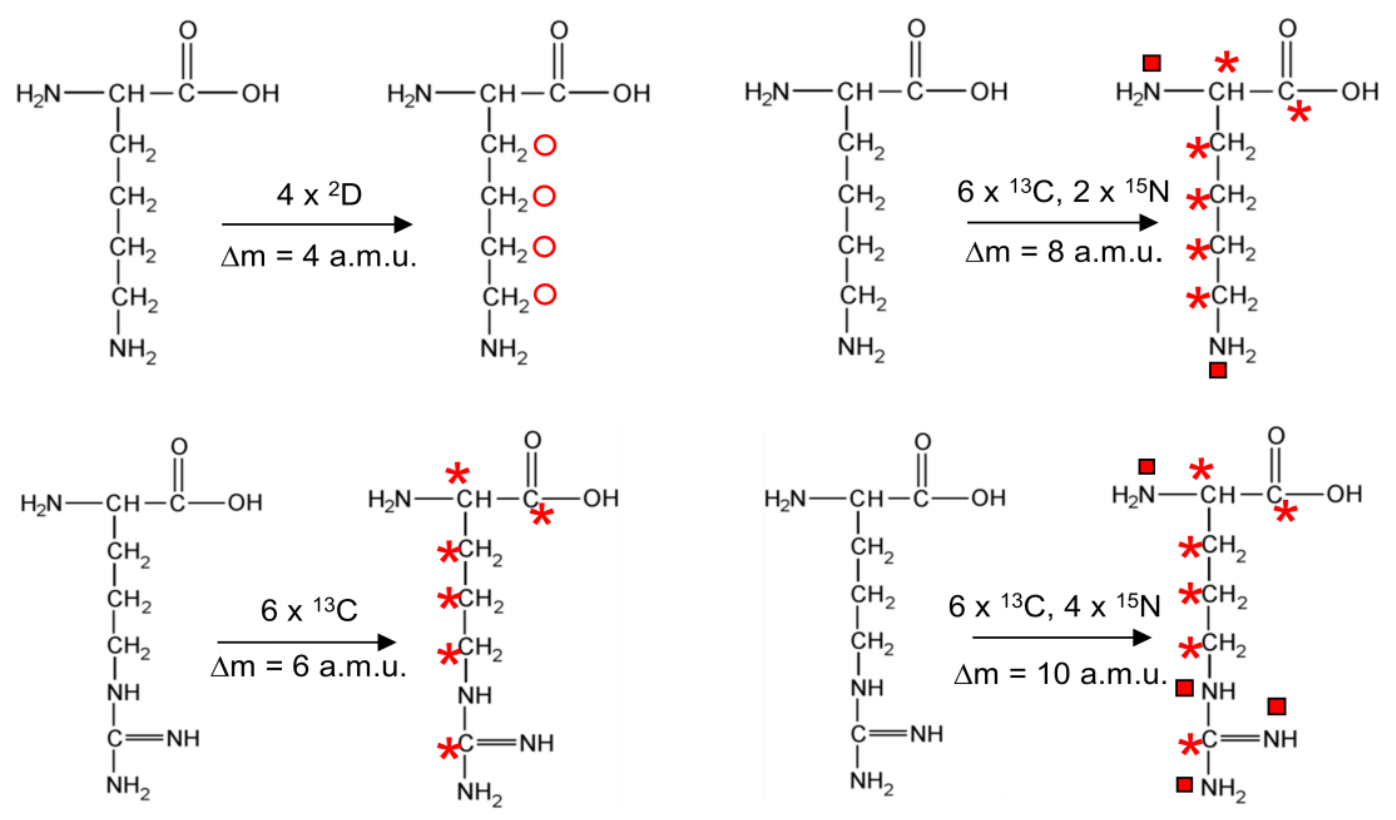

\section{Abb. 4: SILAC-Aminosäuren}

In der oberen Zeile sind Lysin+4 und Lysin+8 dargestellt. Durch den gezielten Einbau von ${ }^{2} \mathrm{D}-,{ }^{13} \mathrm{C}-$ und ${ }^{15} \mathrm{~N}$ Atomen wird ein Massenzuwachs von 4 bzw. 8 a.m.u. generiert. In der unteren Zeile sind Arginin+6 und Arginin+10 dargestellt.

Mittels der Kombination von SILAC und Massenspektrometrie kann man nun Proteine aus unterschiedlichen Zellkulturen relativ quantifizieren. Dabei wird eine Zellkultur in Medium mit natürlichem (leichten) Arginin und Lysin, eine andere Kultur in Medium mit schwerem Arginin und Lysin kultiviert. D.h., dass nach mindestens fünf Zellteilungen nahezu alle Proteine der Zellen einer Kultur leichtes bzw. schweres Arginin und Lysin enthalten. Die Quantifizierung gelingt dadurch, dass, nachdem die Proteine der verschiedenen Kulturen im Verhältnis 1 zu 1 gemischt wurden, das gleiche tryptische Peptid aus den unterschiedlichen Zellkulturen durch die eingebauten Isotopen-markierten Arginine/Lysine einen definierten Massenunterschied zeigt. Anhand der Intensität dieser unterschiedlichen Massenpeaks des gleichen Peptids kann nun eine relative Quantifizierung stattfinden, indem die Intensität des Peptids im schweren Zustand ins Verhältnis mit der Intensität des leichten Peptids gesetzt wird (s. Fig. 6A und 6C, Oellerich et al. 2009, P.1746; Ong et al. 2002). Zur genauen Auswertung solcher quantitativen Daten stehen zwei Softwares zur Verfügung; zum einen MSQuant und zum anderen MaxQuant (Cox und Mann 2008; Mortensen et al. 2010).

Die SILAC-basierte relative Quantifizierung lässt sich für verschiedene Fragestellungen im Bezug auf die Signaltransduktion nutzen. Zum einen ermöglicht sie z. B. die Analyse der BZR-abhängigen Phosphorylierungskinetik einzelner Proteine (Blagoev et al. 2004), zum anderen lässt sie sich nutzen, um spezifische Protein-Protein-Interaktionen zu identifizieren (Blagoev et al. 2003). 
Die Phosphorylierungsanalyse ergab 41 Phosphorylierungsstellen für chSLP65. Unklar ist allerdings, welche dieser zahlreichen Stellen nun in Abhängigkeit vom BZR phosphoryliert werden. Des Weiteren bleibt zu klären, ob die verschiedenen Aminosäurereste mit der gleichen oder doch mit unterschiedlichen Kinetiken nach BZR-Stimulation phosphoryliert werden. Um dieser wichtigen Frage nach der SLP65-Regulation nachzugehen, habe ich ein Experiment durchgeführt, das SILAC, Phosphopeptid-Anreicherung und letzlich massenspektrometrische Analytik kombiniert.

Die ONE-STREP-SLP65 exprimierenden Zellen wurden dazu entweder in Medium mit leichtem Arginin/Lysin, mittelschwerem Arginin(+6)/Lysin(+4) oder schwerem Arginin(+10)/Lysin(+8) kultiviert. Nach Inkorporation der entsprechenden Aminosäuren wurden die drei unterschiedlich markierten Zellkulturen für unterschiedliche Zeiten, nämlich 0, 2 oder 20 Minuten über ihren BZR stimuliert. Daraufhin wurde jeweils SLP65 aus den drei Zellkulturen aufgereinigt (s.o.), das gewonnene Protein im Verhältnis 1 zu 1 zu 1 gemischt und anschließend verdaut, die Phosphopeptide angereichert und letzlich massenspektrometrisch analysiert (s. Fig. 4, Oellerich et al. 2009, P.1743). Für die einzelnen Phosphopeptide wurden MS-Spektren, wie in Abbildung 6A und 6C (Oellerich et al. 2009, P.1746) dargestellt, gewonnen. Die Daten wurden mittels der MSQuant Software ausgewertet, was eine zuverlässige Quantifizierung der einzelnen Phosphopeptide gewährleistete. Auf diese Weise gelang es massenspektrometrisch, die Phosphorylierungskinetik für 21 verschiedene Aminosäurereste zu bestimmen (s. table 1, Oellerich et al. 2009, P.1744). Neben nicht durch den BZR regulierten konstitutiv phosphorylierten Stellen fanden sich im Bezug auf die Phosphorylierungsinetik vier weitere Kategorien. Nämlich a) frühe und transiente, b) frühe und bleibende, c) späte und d) herunterregulierte Phosphorylierungsstellen. Die bisher bekannten Tyrosin-Phosphorylierungsstellen gehören dabei in die Gruppe der früh und transient phosphorylierten Aminosäurereste; dies stimmt gut mit Daten überein, die mittels Antikörper-basierter Techniken gewonnen wurden. Nicht nur die große Anzahl von Phosphorylierungsstellen, sondern auch die differentielle Kinetik der Phosphorylierung zeigt die Komplexität der BZR-abhängigen Signalleitung. SLP65 ist demnach nicht nur, wie bisher angenommen, in die frühe Signalleitung eingebunden. Die Tatsache, dass das Adapterprotein zwanzig Minuten nach BZR-Stimulation noch phosphoryliert wird, bedeutet, dass SLP65 eine wichtige Rolle bei der Signalprozessierung und Integration spielt. SLP65 agiert also nicht nur „upstream“, sondern auch „downstream“ von PLC- $\gamma 2$, welches bereits Sekunden nach BZR-Stimulation aktiviert wird.

\subsection{Phosphorylierung von Serin 173 in SLP65 ist notwendig für die p38- und JNK- Aktivierung}

Um den Einfluss der identifizierten Serin-Phosphorylierung auf die Signalleitung zu untersuchen, habe ich SLP65-defiziente DT40-Zellen mit verschiedenen SLP65-Varianten rekonstituiert und im Hinblick auf $\mathrm{Ca}^{2+}$ - und MAP-Kinasen-Signalleitung untersucht. Durch zielgerichtete Mutagenese konnte ich die 
SLP65-cDNA manipulieren; dabei habe ich einzelne Basen mittels PCR so ausgetauscht, dass sie letztlich in den transfizierten Zellen anstelle von Serin/Threonin für Alanin codieren. Damit ist die Phosphorylierung der jeweils mutierten Aminosäure unmöglich. Die Transfektion der SLP65defizienten DT40-Zellen erfolgte retroviral. Dabei transfizierte ich jeweils eine DT40-Zellkultur mit einem von insgesamt acht verschiedenen SLP65-cDNA-Konstrukten. Im Einzelnen wurden folgende Serine gegen Alanin ausgetauscht: S65, S84, S170, S173, S339, S381, S382 und T451. Die einzelnen DT40-Zellkulturen, die ja jeweils ein an unterschiedlicher Stelle mutiertes SLP65 exprimierten, wurden dann im Vergleich zu Zellen, die wildtypisches SLP65 exprimierten, untersucht.

Im Hinblick auf die BZR-abhängige $\mathrm{Ca}^{2+}$-Mobilisierung verhielten sich alle SLP65-Varianten wie wildtypisches SLP65 (Daten nicht gezeigt und s. Fig. 8B, Oellerich et al. 2009, P.1747). Allerdings zeigte die SLP65-S170A Variante eine erheblich reduzierte Aktivierung von p38 und JNK, welche mittels Phosphostellen-spezifischen Antikörpern im Western-Blot nachgewiesen werden konnte (s. Fig. 9 B und 9C, Oellerich et al. 2009, P.1748). Auf Genebene lies sich passend dazu im Luciferase basierten Reportergen-Versuch eine verminderte AP-1-Aktivität in den Zellen, die SLP65-S170A exprimierten, nachweisen (s. Fig. 9D, Oellerich et al. 2009, P.1748). Dies bedeutet, dass die BZRabhängige Phosphorylierung von Serin 170 für die Regulierung der vom Transkriptionsfaktor AP-1 gesteuerten Genexpression wichtig ist. Des Weiteren konnte ich zeigen, dass Serin 170 nur in Abhängigkeit von Phospho-Serin 173 phosphoryliert werden kann (s. Fig. 7B, Oellerich et al. 2009, P.1747). Diese hierarchische Phosphorylierung stellt somit einen $\mathrm{Ca}^{2+}$ - unabhängigen Regulationsmechanismus von den MAP-Kinasen JNK und p38 dar.

\subsection{Spezifische Identifikation von Protein-Protein-Interaktionen mittels quantitativer Massenspektrometrie}

Im Folgenden möchte ich eine Methode beschreiben, die es ermöglicht, spezifisch und zuverlässig Protein-Protein-Interaktionen zu identifizieren (Blagoev et al. 2003). Angewendet habe ich diese Methode zur Charakterisierung der durch die Adapterproteine SLP65- bzw. Grb2-vermittelten Signalkomplexe.

Prinzipiell werden bei einer wie oben beschriebenen Proteinaufreinigung nicht nur das getaggte Protein selbst, sondern auch dessen Interaktionspartner angereichert. Nach Auftrennung der aufgereinigten Proteine mittels SDS-Gelelektrophorese und Verdau der gesamten Coomassiegefärbten Proteinspur wäre es im Idealfall möglich, das getaggte Protein und die einzelnen Komplexbestandteile massenspektrometrisch zu identifizieren. Allerdings ergab eine Analyse einer solchen Spur in etwa tausend verschiedene Proteine, wovon der größte Teil unspezifisch mit der Aufreinigungsmatrix interagierende Proteine darstellte. Es ist daher unmöglich zu unterscheiden zwischen Proteinen, die spezifisch mit dem getaggten Protein oder aber unspezifisch mit der 
Sepharose-Matrix interagieren. Auch die Hinzunahme einer Negativkontrolle schuf in Vorversuchen keine Abhilfe. Der Gedanke war, die unspezifischen Proteine zu identifizieren, indem man die gleiche Aufreinigung mit Zellen durchführt, die kein getaggtes SLP65 enthalten (s. Abb.3). Somit würden nur unspezifische Proteine angereichert und identifiziert. Diese Proteine könnte man dann von denen, die in der den Proteinkomplex enthaltenden Spur identifiziert wurden, abziehen. Somit würden nur solche übrig bleiben, die spezifisch mit dem getaggten Protein interagieren. Aus messtechnischen Gründen, so stellte sich heraus, ist dies nicht möglich. Das Massenspektrometer selektiert nämlich eine bestimmte Anzahl von Peptiden im Hinblick auf deren Intensität. Das bedeutet, dass nicht zwangsläufig die gleichen Proteine in der Negativkontrolle und der Probe identifiziert werden. Eine vollständige Erfassung der unspezifischen Proteine ist also auf diesem Weg nicht möglich.

Die Kombination aus SILAC und massenspektrometrischer Analytik ermöglicht, wie bereits beschrieben, die Quantifizierung von Proteinen. Der quantitative Ansatz lässt sich nutzen, um die spezifisch interagierenden Proteine zu identifizieren (Blagoev et al. 2003). Den Versuchsablauf möchte ich für die Bestimmung des SLP65-Komplexes beschreiben.

Wildtypische DT40-Zellen (Negativkontrolle) wurden in „leichtem“ SILAC-Medium kultiviert, während die ONE-STREP-SLP65-exprimierenden Zellen in „schwerem“ SILAC-Medium kultiviert wurden. Nach Lyse der Zellen wurde wie oben beschrieben die Proteinaufreinigung mittels Streptactin-Matrix durchgeführt. Dabei enthielt das Eluat, das nach Aufreinigung aus dem Lysat der „leichten“ Zellen gewonnen wurde, lediglich die unspezifischen Proteine; dasjenige aus dem Lysat der „schweren“ ONE-STREP-SLP65-exprimierenden Zellen hingegen sowohl die unspezifischen Proteine als auch SLP65 und die Komponenten des SLP65 Komplexes. Die Eluate wurden im Verhältnis 1 zu 1 gemischt, durch SDS-Gelelektrophorese aufgetrennt und mittels Coomassie-Lösung gefärbt. Die Spur wurde anschließend in 23 Banden geteilt, die enthaltenen Proteine verdaut und anschließend mit einem LTQ-Orbitrap-XL-Hybrid-Massenspektrometer analysiert (s. Fig. S1, Oellerich et al. 2011). Die Daten wurden dann mit der Software MaxQuant analysiert (Cox et al. 2009); die Datenverteilung einer solchen Messung ist in Abb. 6 dargestellt. 


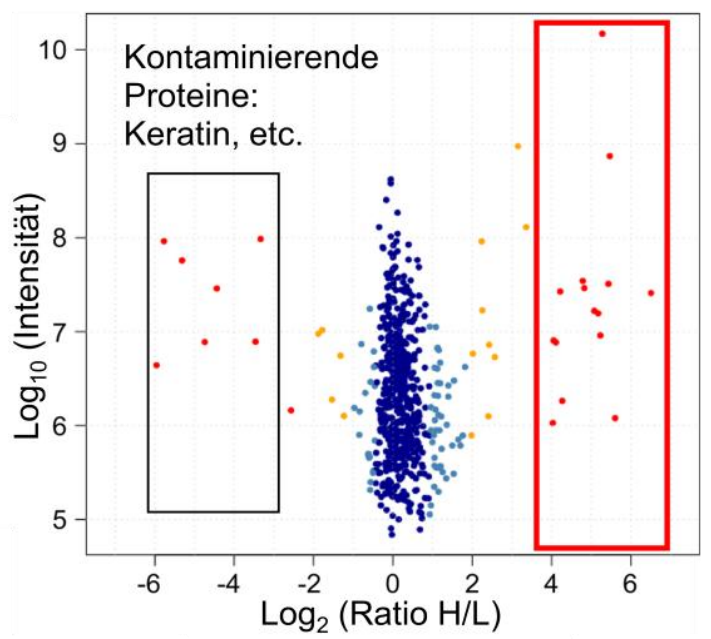

Abb.6: Datenverteilung einer SILAC-basierten Messung

Jeder Punkt im Diagramm stellt ein massenspektrometrisch identifiziertes Protein dar. Aufgetragen sind logarithmisch die Intensität der Massenpeaks über der Ratio von schweren Peptiden zu leichten (H/L). Interaktionspartner von SLP65 liegen in der roten Box; Kontaminationsproteine in der schwarzen Box. Der Farbcode der einzelnen Proteine gibt den Signifikanzbereich an: rot: $\mathrm{p}<10^{-10}$, gelb: $\mathrm{p}<10^{-5}$, hellblau: $\mathrm{p}<10^{-4}$, blau: $\mathrm{p}<10^{-1}$.

Für den größten Teil der Proteine ergab sich ein Verhältnis von nahezu 1 zu 1. Das bedeutet, dass diese Proteine sowohl in der Negativkontrolle als auch in der Probe in gleichem Maße vorhanden sind. Damit sind diese Proteine unspezifisch aufgereinigt; die Ratio „Schwer zu Leicht“ liegt für diese Proteine in meinen Experimenten ca. zwischen 0.3 und 3. Solche Proteine hingegen, die verstärkt im schweren Zustand auftreten (demnach eine Ratio größer 3 aufweisen), können als spezifisch angesehen werden. Um jegliche falsch positive Interaktionspartner auszuschließen, wurden nur Proteine mit einer Ratio größer 5 als Interaktionspartner gewertet (Abb.6, rote Box; s. table 1, Oellerich et al. 2011, P.3623). Hingegen die Proteine, die eine Ratio kleiner 0,3 aufweisen, sind solche Kontaminationsproteine wie Keratin oder auch Trypsin. Diese Proteine sind nachträglich von außen in die Probe gelangt und liegen demnach im nicht markierten Zustand vor (Abb.6, schwarze Box).

Analog zum SLP65-Komplex konnte ich auf diese Weise den durch das Adapterprotein Grb2 vermittelten Komplex identifizieren (s. table 1, Neumann et al. 2009, P.142-143). Bereits bekannte Komplexkomponenten dienten in beiden Experimenten als Positivkontrolle und wurden größtenteils erfolgreich identifiziert.

Der SLP65-Komplex wurde sowohl aus unstimulierten als auch BZR-stimulierten B-Zellen aufgereinigt. In unstimulierten Zellen konnten 6 Interaktionspartner bestimmt werden, nämlich Grb2, CIN85, CD2AP, CapZ, „Heat shock“ proteine und Unc119B. Nach Stimulation findet eine erhebliche Reorganisation des Komplexes statt. Insgesamt konnten nach Stimulation 29 interagierende Proteine 
identifiziert werden, wovon 20 bisher unbekannt waren (s. Abb. 7; table 1, Oellerich et al. 2011, P.3623). Funktionell lassen sich diese Proteine verschiedenen Gruppen zuordnen. Dabei gehören z.B. Dok-3, Btk und PLC- $\gamma 2$ zu den $\mathrm{Ca}^{2+}$-Regulatoren; Cap-Z, Profilin, Talin-1 und Nck zu den Regulatoren des Zytoskeletts, wobei für Profilin eine Rolle in der Regulation von $\mathrm{IP}_{3}$ in anderen Zellsystemen beschrieben ist (Machesky et al. 1990). Mapkk4, welche Aktivator von p38 und JNK ist, wie auch Vav3 sind prominente Mitglieder der Map-Kinase-Signalleitung. Auch die Kinasen Lyn und Syk konnten im SLP65-Komplex nachgewiesen werden, wobei Syk nur spät nach BZR-Stimulation Teil des Komplexes wird. Dies stimmt mit publizierten Daten überein, die eine späte Interaktion zwischen SLP65 und Syk im Zuge des „sustained BCR signaling“ beschrieben (Kulathu et al. 2008). Ein interessanter neu identifizierter Ligand ist das „C-type lectin domain family member 17A“ (CLEC17A), welches ein Transmembranprotein darstellt. Im zytoplasmatischen Anteil des Proteins befinden sich Bindungsstellen für SH2- und SH3-Domänen. Ein solches Molekül könnte für die Membranrekrutierung von BZR-Effektoren verantwortlich sein. Außer HPK-1 wurden alle bisher bekannten Interaktionspartner identifiziert.

Um die identifizierten Protein-Protein-Interaktionen mit einer weiteren Methode zu bestätigen, wurden Co-Immunpräzipitationen durchgeführt. D.h., SLP65 wurde mittels Antikörpern aus humanem B-ZellLysat aufgereinigt, und ein Teil der durch Massenspektrometrie ermittelten Interaktionspartner im Western-Blot mittels spezifischer Antikörper nachgewiesen (s. Fig. 1E, Oellerich et al. 2011, P.3622).

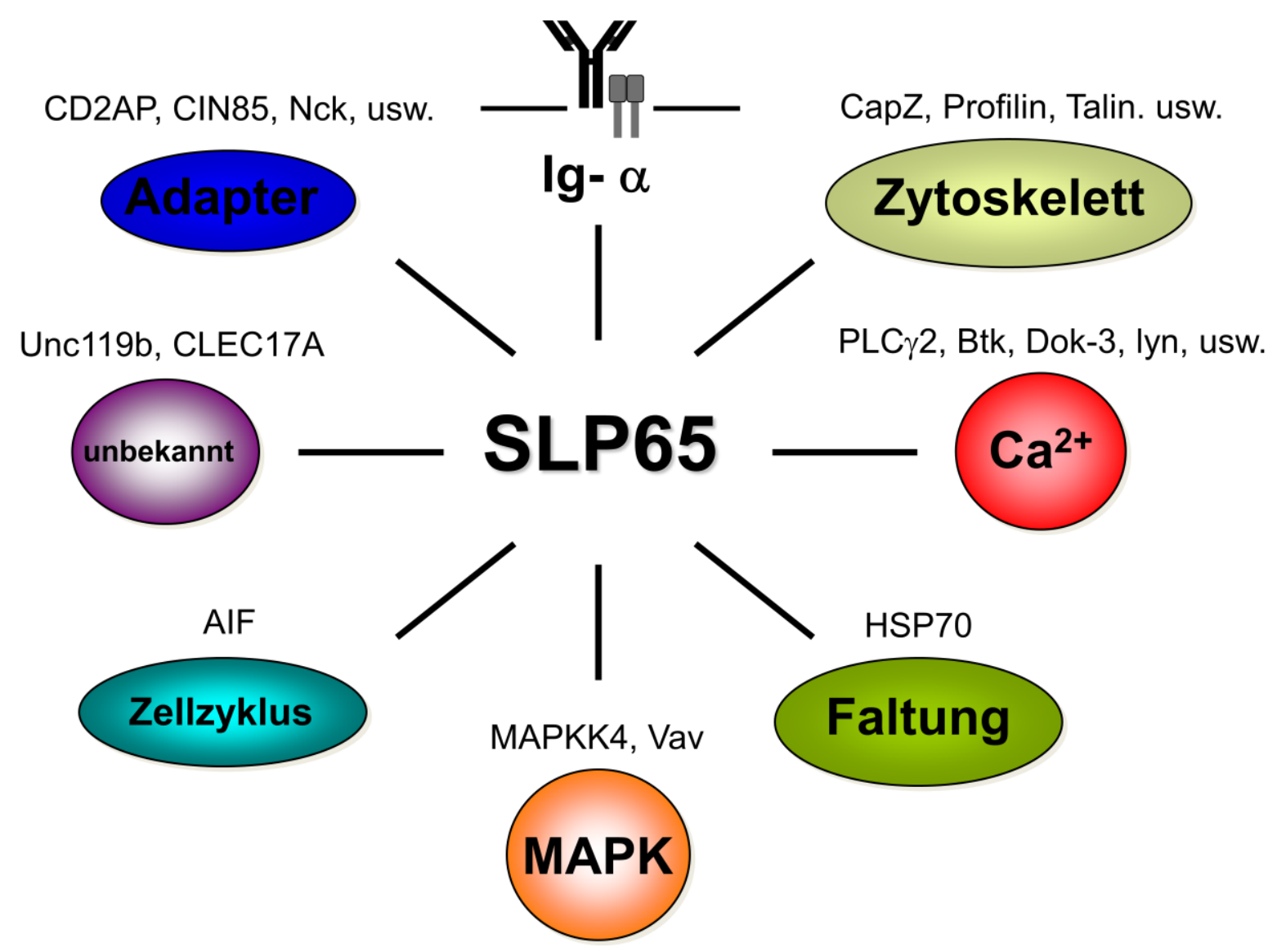




\section{Abb.7: Der SLP65-Komplex}

Schematische Darstellung der identifizierten Komponenten des SLP65-Komplexes. Die einzelnen Proteine sind nach Literatur den entsprechenden funktionellen Gruppen zugeordnet. (Adaptiert nach einer Vorlage von Prof. Dr. J. Wienands)

Analog zu dem beschriebenen Verfahren identifizierte ich die Komponenten des durch Grb2 vermittelten Multiproteinkomplexes.

Grb2 ist ein Adapterprotein, das eine zentrale SH2-Domäne enthält, die beidseits von jeweils einer SH3-Domäne flankiert wird. Aus anderen Zelltypen sind zahlreiche Grb2-vermittelte Proteininteraktionen bekannt; in B-Zellen hingegen nur wenige, u.a. diejenige mit SLP65.

Grb2 ist ein Adapterprotein, das durch Assemblierung verschiedener Signalkomplexe die BZRSignalleitung sowohl inhibitorisch als auch aktivatorisch beeinflussen kann (Stork et al. 2004; Stork et al. 2007). Damit ist Grb2 wichtig zur Signalregulation und -integration, welche für die physiologische Balance zwischen B-Zell-Aktivierung und Toleranz notwendig ist (Ackermann et al. 2011).

Die Interaktion von Grb2 mit inhibitorischen Co-Rezeptoren wie FcyRIIb und CD22 verstärkt deren inhibitorische Wirkung durch Stabilisierung der FcyRIIb-SHIP- bzw. der CD22-SHP-2-Interaktion. Auch im Komplex mit Dok-3 wirkt Grb2 inhibitorisch und reduziert die BZR-vermittelte $\mathrm{Ca}^{2+}$ Freisetzung. Im Gegensatz dazu wirkt Grb2 im Komplex mit NTAL oder CD19 aktivatorisch (Stork et al. 2004). Je nach Verteilung von Grb2 in den verschiedenen Signalosomen, beeinflusst es die B-ZellAntwort nach Antigen-Erkennung. Um weitere Interaktionspartner des Adapterproteins zu identifizieren und damit das regulatorische Netzwerk in B-Zellen weiter aufzuschlüsseln, habe ich mit der oben beschriebenen Methode das „Grb2-Interaktom“ in B-Zellen identifiziert. Dabei ergaben sich insgesamt 27 interagierende Proteine, wovon 11 bisher nicht beschrieben waren. Insbesondere die Protein-Tyrosin-Phosphatasen PTPRa und PTP-PEST stellen interessante potentielle B-ZellRegulatoren dar; für die Phosphatasen der PEST Familie gibt es bereits zahlreiche Daten, die deren Relevanz in Bezug auf Immunzell-Aktivierung und Autoimmunität deutlich machen. Die gesamte Liste der mit Grb2 interagierenden Proteine ist in Tabelle 1 (Neumann und Oellerich et al. 2009) dargestellt.

\subsection{Die Dynamik der SLP65-mediierten Protein-Protein-Interaktionen in Abhängigkeit von der BZR-Stimulation}

Analog zur Bestimmung der Phosphorylierungskinetik lässt sich mittels SILAC-basierter Massenspektrometrie auch die Kinetik der stimulationsabhängigien Protein-Protein-Interaktionen bestimmen. Der Versuchsaufbau gleicht vom Prinzip demjenigen, der zur Bestimmung der Phosphoylierungskinetik angewendet wurde. Er ist in Fig. 1A (Oellerich et al. 2011, P.3622) 
schematisch dargestellt. Der einzige Unterschied zum Versuchsaufbau zur Identifizierung der Phosphorylierungsstellen ist, dass zur Analyse der Dynamik der Proteininteraktionen die gesamte Coomassie-gefärbte Spur, also 23 Banden, massenspektrometrisch analysiert wurde und zudem keine phospho-Peptid-Anreicherung stattgefunden hat. Die Kinetik der SLP65-vermittelten Proteininteraktionen habe ich nicht nur für drei, sondern für fünf Zeitpunkte nach BZR-Stimulation bestimmt. Dies machte die Kombination von zwei SILAC-Experimenten erforderlich. Im ersten Experiment wurde die Kinetik der Proteininteraktionen nach 0, 2 und 20 Minuten BZR-Stimulation bestimmt. Im zweiten dann für 0, 5 und 10 Minuten. Die MaxQuant-Software konnte dann die Daten im Bezug auf die Werte für die 0-minütige Stimulation normalisieren und anschließend zusammenfassen (Cox und Mann 2008).

Die Interaktionspartner von SLP65 waren aus dem unter 2.4 beschriebenen Experiment bereits bekannt. Nun konnte nach MaxQuant-gestützter Quantifizierung die Kinetik für 18 der insgesamt 29 interagierenden Proteine bestimmt werden. Im Bezug auf die Bindungskinetik lassen sich drei Hauptgruppen unterscheiden. Zum einen gibt es Proteine die nach BZR-Stimulation früh, aber transient mit SLP65 interagieren. Zu dieser Gruppe zählen bereits bekannte Interaktionspartner wie PLC- $\gamma 2$, Vav3, Nck und Grb2; aber auch neu identifizierte Komponenten des SLP65-Komplexes wie CLEC17A, Profilin, Lyn und andere machen diese Gruppe aus. CapZ und Protein-Phosphatase-2 hingegen interagieren erst 10 Minuten nach BZR-Stimulus mit SLP65. Sie zählen somit zu der Gruppe der späten Interaktionspartner. Die dritte Gruppe wird von Proteinen wie CIN85, CD2AP und Unc119B gebildet. Diese Proteine interagieren konstant und unabhängig von der BZR-Stimulation mit SLP65 (s. Fig. 1B,C und D, Oellerich et al. 2011, P.3622). Insbesondere konnte die BZRunabhängige, also präformierte Interaktion von CIN85 bzw. CD2AP mit SLP65 mittels CoImmunpräzipitation in Lysaten von BZR-defizienten J558L B-Zellen gezeigt werden (Abb. 8 und s. Fig. 1F, Oellerich et al. 2011, P.3622).

Für einige Proteine wie Sek1, CapZ, Dok3, CD2AP und Grb2 habe ich zudem die Interaktionskinetik mittels Co-Immunpräzipitation in Lysaten von humanen B-Zellen bestätigt (s. Fig. 1E, Oellerich et al. 2011, P.3622). 


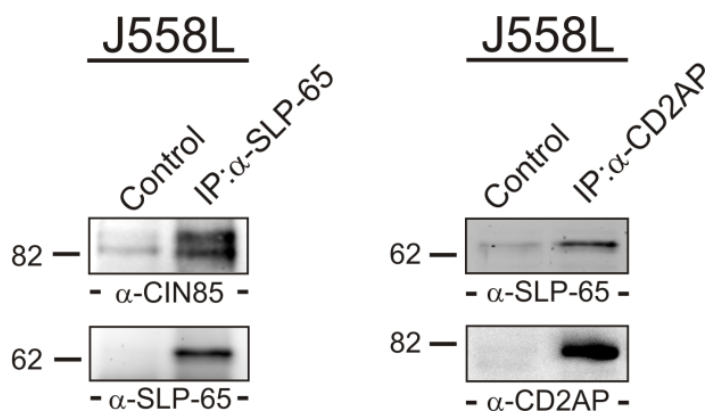

Abb.8: Der präformierte SLP65-Komplex

Co-Immunpräzipitation von SLP65 und CIN85 sowie SLP65 und CD2AP in Lysaten von J558L-Zellen. Diese Zellen exprimieren keinen BZR. Als Kontrolle diente eine Immunpräzipitation mit einem unspezifischen Antikörper des gleichen Isotyps wie der jeweils präzipitierende Antikörper gegen SLP65 bzw. CD2AP.

\subsection{Die Funktion der präformierten Interaktion von CIN85/CD2AP und SLP65}

CIN85 und CD2AP sind zwei 85 bzw. 80kDa große Adapterproteine, die jeweils N-terminal drei SH3Domänen und C-terminal eine „coiled-coil“-Region aufweisen. Getrennt werden diese Strukturen durch mehrere prolinreiche Regionen. Zu der Funktion von CIN85 und CD2AP in B-Zellen ist bisher nichts bekannt, wohl aber in anderen Zelltypen einschließlich T-Lymphozyten und Podozyten (Dikic 2002).

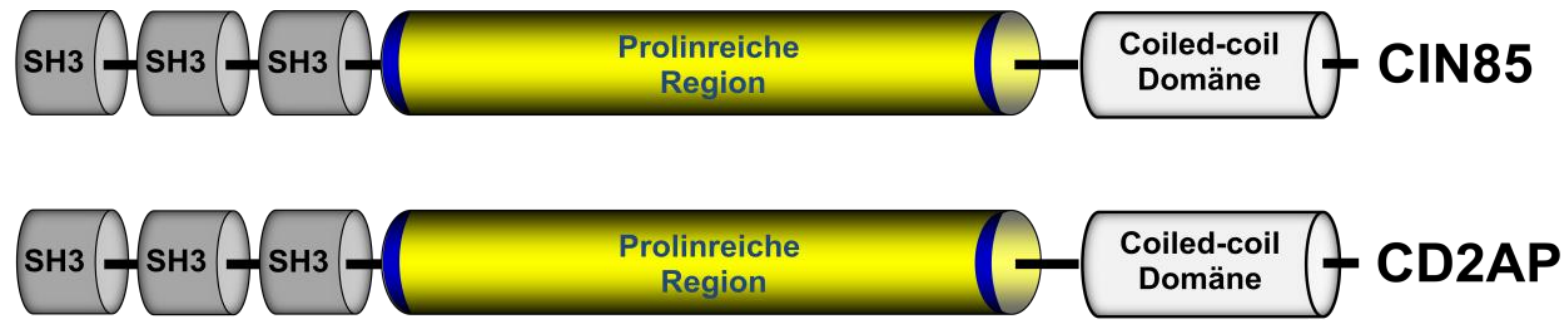

\section{Abb.9: Domänen-Struktur von CIN85 und CD2AP}

N-terminal befinden sich drei SH3-Domänen, welche das Konsensusmotiv PXXXPR erkennen. Den SH3Domänen folgt eine prolinreiche Region. Am C-Terminus befindet sich eine „Coiled-coil“-Domäne, welche Protein-Protein-Interaktionen vermittelt. Zudem bindet diese Domäne ,phosphatidic acid“(PA).

CIN85 ist in eine Reihe von Signalpfadwegen eingebunden und spielt eine wichtige Rolle bei der Rezeptorendozytose (z.B. des Ig-E-Rezeptors in Mastzellen) und der lysosomalen Degradation von Rezeptor-Tyrosin-Kinasen (Molfetta et al. 2005; Peruzzi et al. 2007). Mittels seiner SH3-Domänen 
bindet das Adapterprotein vornehmlich die Ubiquitin-Ligase Cbl (Take et al. 2000). Eine Reihe anderer Interaktionen ist bereits beschrieben, wie z.B. die mit den „Actin-Capping“-Proteinen der CapZ Familie, Grb2 und Lyn (Watanabe et al. 2000).

CD2AP wurde erstmals von Dustin et al. als Organisator der immunologischen Synapse in T-Zellen beschrieben (Dustin et al. 1998). Dabei spielt CD2AP u.a. eine entscheidende Rolle für das „TCR clustering“ nach Kontakt der T-Zelle mit Antigen-präsentiernden Zellen. Im Allgemeinen scheint CD2AP insbesondere als Adapterprotein zwischen Membranproteinen und dem Zytoskelett zu fungieren. Die Relevanz seiner Funktion wird insbesondere in Podozyten, welche kein CD2AP exprimieren, deutlich. Dort ist es nämlich verantwortlich für die Verankerung der PodozytenSchlitzmembran im Aktin-Zytoskelett (Shih et al. 2001). CD2AP defiziente Mäuse sterben bereits in den ersten Lebenswochen an Nierenversagen (Shih et al. 1999).

Bereits 1996 konnten Wienands et. al. zeigen, dass präformierte Signalkomplexe die Signalleitung in B-Zellen ermöglichen (Wienands et al. 1996). Die Zusammensetzung dieser präformierten Komplexe blieb jedoch unklar. Aus den oben beschriebenen Proteomstudien ergibt sich, dass SLP65 in unstimulierten Zellen im Komplex mit CIN85 und/oder CD2AP vorliegt. Unter der Annahme, dass der präformierte Komplex bestehend aus SLP65 und CIN85/CD2AP für die Rekrutierung und Aktivierung von SLP65 verantwortlich ist, habe ich diesen Signalkomplex näher untersucht.

Die SH3-Domänen von CIN85 binden an prolinreiche Sequenzen mit der Aminosäuresequenz PxxxPR bzw. PxPxPR (Kowanetz et al. 2003). Dieses Motiv kommt dreimal in humanem oder auch murinem SLP65 vor (s. Fig. 2A, Oellerich et al. 2011, P.3625). Um nun die Funktion der präformierten Interaktion zwischen CIN85 bzw. CD2AP und SLP65 zu untersuchen, habe ich SLP65defiziente DT40-Zellen mit SLP65 rekonstituiert, welches nicht mehr in der Lage ist, CIN85 oder CD2AP zu binden. Dazu habe ich mittels Mutagenese PCR die SLP65-cDNA so verändert, dass anstelle von Arginin (+5 Position im PxxxPR-Motiv) für Alanin codiert wird. Nach retroviraler Transfektion stand eine DT40-Zellkultur zur Verfügung, die wildtypisches GFP-markiertes SLP65, und eine andere, die GFP-SLP65-R49,248,313A (kurz: R-to-A) exprimiert. Mittels CoImmunpräzipitation konnte ich zeigen, dass das mutierte SLP65 nicht mehr in der Lage ist, CIN85 und CD2AP zu binden (s. Fig. 2B, Oellerich et al. 2011, P.3625).

Um nun die Auswirkung der in SLP65 eingefügten Punktmutationen auf den SLP65-Gesamtkomplex zu zeigen, habe ich ein SILAC-basiertes Experiment durchgeführt; dieses Verfahren bezeichnen wir als „Reverse Proteomics“. Dabei habe ich DT40-Zellen hergestellt, die entweder ONE-STREPSLP65-wt oder aber ONE-STREP-SLP65-R-to-A exprimieren. Diese habe ich analog zu dem unter 2.4 beschriebenen Experiment in „leichtem“ bzw. „schwerem“ SILAC-Medium kultiviert. Nach drei Minuten andauernder BZR-Stimulation erfolgte die Aufreinigung von SLP65 aus den entsprechenden Zelllysaten. Danach wurden „leichte“ und „schwere“ Proteine wieder im Verhältnis 1 zu 1 gemischt, elektrophoretisch aufgetrennt und die gesamte Coomassie-gefärbte Spur massenspektrometrisch 
analysiert. Nach MaxQuant-gestützter Auswertung ließ sich auch auf diesem Weg nachweisen, dass SLP65-R-to-A nicht mehr in der Lage ist, CIN85 und CD2AP zu binden (s. Fig. 3E, Oellerich et al. 2011, P.3626). Des Weiteren zeigte sich, dass neben CapZ auch PLC- $\gamma 2$, Nck und Vav3 nahezu nicht mehr an SLP65-R-to-A binden. Auch Grb2 zeigt eine signifikant verminderte Interaktion. Dies legt nahe, dass die eingefügten Punktmutationen nicht nur die Interaktion zwischen CIN85/CD2AP und SLP65 aufheben, sondern auch einen erheblichen Einfluss auf die SLP65-Tyrosinphosphorylierung haben. PLC- $\gamma 2$, Vav3, Nck und auch Grb2 (Grb2 zumindest teilweise) interagieren nämlich erst mit SLP65, nachdem es an bestimmten Tyrosinresten durch Syk phosphoryliert wurde (s.o.).

In den GFP-SLP65-wt bzw. -R-to-A-exprimierenden Zellen habe ich daraufhin die BZR-Signalleitung untersucht. Nach ein bzw. drei Minuten andauernder Stimulation, habe ich die Aktivierung von Lyn, Syk, SLP65 und PLC- $\gamma 2$ untersucht. Dazu habe ich im Falle der Kinasen deren Aktivierung im Western-Blot mittels Phospho-Stellen-spezifischer Antikörper nachgewiesen. In beiden Zellkulturen, so zeigte sich, wurden die Kinasen in gleichem Ausmaß phosphoryliert und damit aktiviert (Abb.10 bzw. Fig. 3D, Oellerich et al. 2011, P.3626). Im Gegensatz dazu zeigte sich sowohl für SLP65 als auch für PLC- $\gamma 2$ eine nahezu aufgehobene Tyrosinphosphorylierung nach BZR-Stimulation in den Zellen (Abb.10 bzw. Fig. 3B, Oellerich et al. 2011, P.3626), die SLP65-R-to-A exprimierten; es besteht also ein Block in der Signalleitung zwischen aktiviertem Syk und SLP65, sobald SLP65 nicht mehr mit CIN85/CD2AP interagiert. Welches der beiden Proteine, entweder CIN85 oder CD2AP, oder ob beide Proteine für die SLP65-Aktivierung notwendig sind, bleibt dabei allerdings noch unklar.
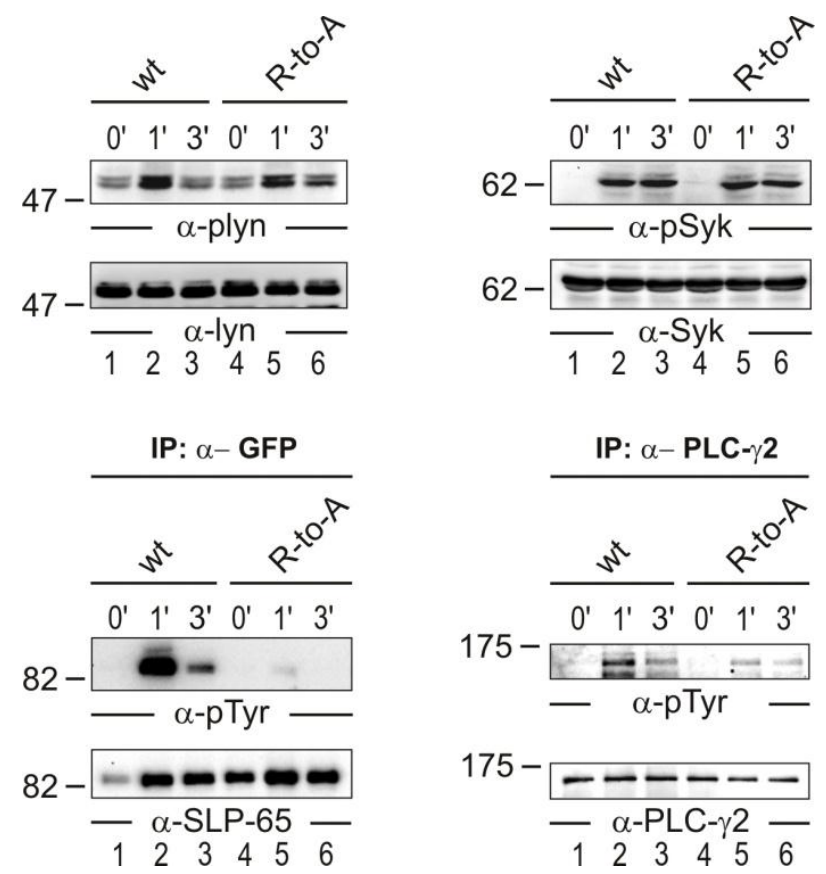

\section{Abb.10: Untersuchung der Phosphorylierung von Effektoren der BZR-abhängigen Signalleitung \\ Rekonstituierte SLP65-defiziente DT40-B-Zellen, die entweder wildtypisches SLP65 oder SLP65-R-to-A exprimierten, wurden für die angegebene Zeit über den BZR stimuliert. Nach Herstellung zellulärer Lysate}


wurde im Western-Blot-Verfahren mittels Phospho-Stellen-spezifischen Antikörpern die Aktivierung von den Kinasen Lyn und Syk untersucht (obere Zeile).

Zur Untersuchung der Phosphorylierung von SLP65 und PLC- $\gamma 2$ wurden diese Proteine zunächst aus Lysaten der o.g. Zellen mittels entsprechender Antikörper präzipitiert; im Western-Blot-Verfahren konnte anschließend mit Antikörpern gegen phospho-Tyrosin die Aktivierung der Proteine nachgewiesen werden (untere Zeile). Als Ladekontrolle erfolgten Western-Blots mit Antikörpern gegen Lyn, Syk, SLP65 und PLC- $\gamma 2$ (s. jeweils unterer Blot in oberer und unterer Zeile).

In den gleichen Zellen habe ich zudem durchflusszytometrisch die BZR-abhängige $\mathrm{Ca}^{2+}$-Mobilisierung untersucht. Passend zur verminderten SLP65-R-to-A-Tyrosinphosphorylierung, zeigten diese Zellen eine nahezu aufgehobene $\mathrm{Ca}^{2+}$-Freisetzung (s. Abb. 11 bzw. Fig. 3A, Oellerich et al. 2011, P.3626). Außerdem ließ sich in diesen Zellen keine Aktivierung des NFkB-Signalwegs nachweisen (s. Fig. 3C, Oellerich et al. 2011, P.3626). Um nun einen Hinweis darauf zu bekommen, welches der drei in SLP65 vorkommenden CIN85/CD2AP-bindenden PxxxPR-Motive funktionell am bedeutendsten ist, habe ich auch Zellen, die SLP65 mit den entsprechenden Einzelmutationen exprimierten, untersucht. Dabei zeigte sich, dass R248 und R313 im Wesentlichen für die SLP65-Aktivierbarkeit verantwortlich sind (s. Abb. 11 bzw. Fig. 3A, Oellerich et al. 2011, P.3626). In Kooperation mit den Dres. rer. nat. Michael Engelke und Kai Dittmann konnte ich zudem den gleichen Effekt von SLP65-R-to-A auf die $\mathrm{Ca}^{2+}$-Mobilisierung in primären Maus-B-Zellen nachweisen (s. Fig. 3A, Oellerich et al. 2011, P.3626). Dazu wurden aus slp65-defizienten Mäusen die Splenozyten mittels CD19-bindenden magnetischen Beads aufgereinigt und retroviral unter LPS-Stimulation mit SLP65-wt-Citrin bzw. -R-to-A-Citrin transfiziert. Nach Stimulation konnte die $\mathrm{Ca}^{2+}$-Mobilisierung in diesen Splenozyten gemessen werden. Diese war in den SLP65-R-to-A-exprimierenden und den SLP65-defizienten B-Zellen in etwa gleich schwach. Die marginale $\mathrm{Ca}^{2+}$-Freisetzung in den SLP65-defizienten primären B- Zellen wird durch die kompensatorische Expression von LAT und SLP76 in diesen Zellen möglicherweise erklärt (Wong et al. 2000). 

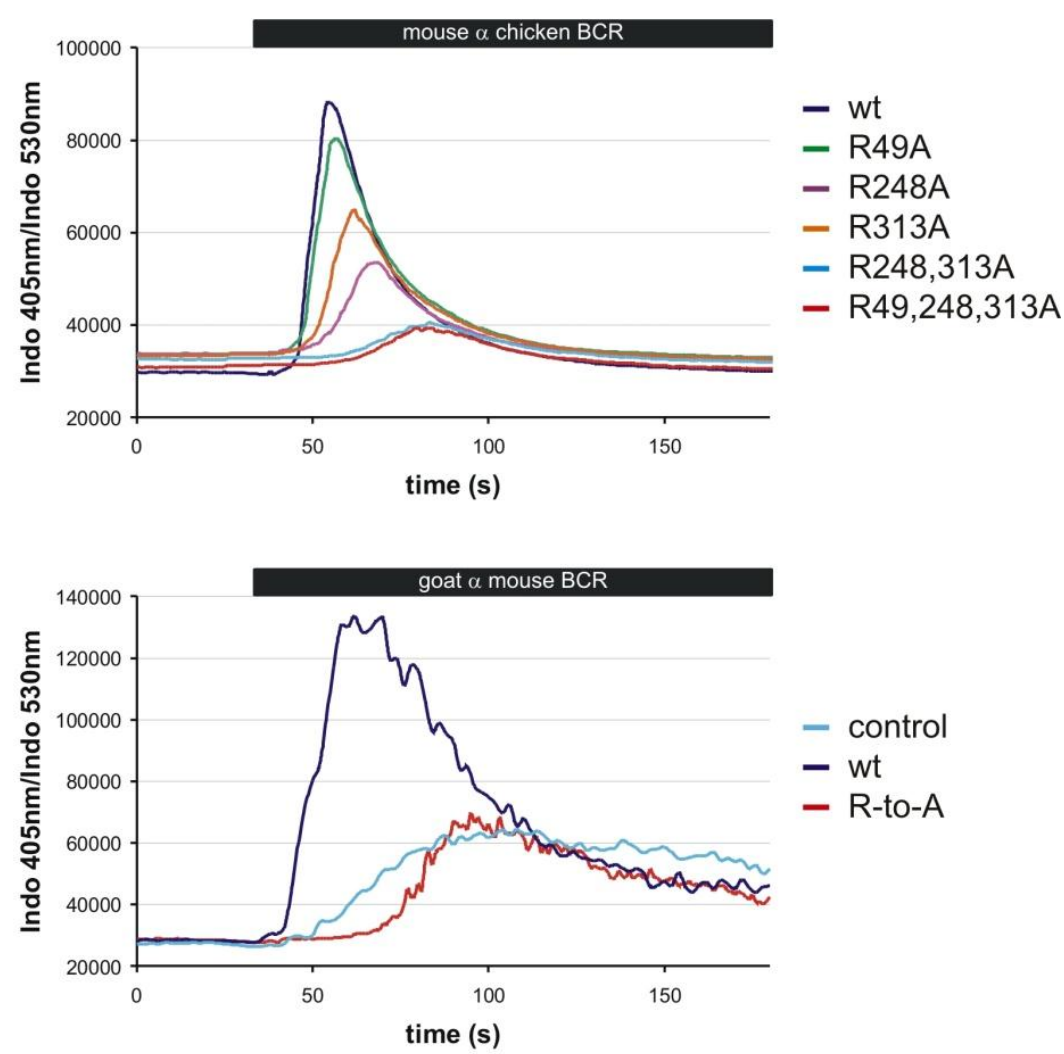

\section{Abb. 11: $\mathrm{Ca}^{2+}$ - Signale in rekonstituierten DT40- und primären B-Zellen}

SLP65-defiziente DT40- bzw. primäre B-Zellen wurden mit wildtypischem SLP65 oder mit den in der Abbildung beschriebenen Varianten von GFP-markiertem SLP65 rekonstituiert. Nach Beladung dieser Zellen mit dem $\mathrm{Ca}^{2+}$-Chelator INDO-1-AM wurden die entsprechenden Zellen über ihren BZR stimuliert und die $\mathrm{Ca}^{2+}$ Mobilisation mittels Durchflusszytometrie gemessen.

Die Interaktion von SLP65 mit CIN85/CD2AP ist notwendig dafür, dass SLP65 im Zuge der BZRStimulation von Syk phosphoryliert werden kann. Mechanistisch gesehen könnte dies bedeuten, dass CIN85/CD2AP dafür verantwortlich sind, SLP65 zu den aktivierten BZR zu rekrutieren. Denn erst dort kann SLP65 phosphoryliert und damit aktiviert werden.

Um diese Frage nach der SLP65-Membranrekrutierung zu klären, habe ich die Rekrutierung von der SLP65-R-to-A Variante mittels konfokaler Mikroskopie in DT40- und primären Maus-B-Zellen untersucht. SLP65-wt und die -R-to-A-Variante wurden dazu C-terminal mit Citrin markiert. Mittels retroviraler Transfektion wurden die SLP65-defizienten DT40- bzw. primären B-Zellen entweder mit wildtypischem oder entsprechend mutiertem SLP65 rekonstituiert. Wildtypisches SLP65 zeigte nach BZR-Stimulation eine deutliche Membranrekrutierung sowohl in DT40- als auch in den primären BZellen (s. Fig. 4A und 4B (obere Spalte), Oellerich et al. 2011, P.3627). Im Gegensatz dazu konnte keine Membranrekrutierung der SLP65-R-to-A-Variante nachgewiesen werden (s. Fig. 4A und 4B (untere Spalte), Oellerich et al. 2011, P.3627). Dies steht im Einklang mit den Daten, die zeigen, dass SLP65-R-to-A nicht durch Syk aktiviert werden kann. Demnach kann SLP65 nur im Komplex 
zusammen mit CIN85/CD2AP rekrutiert werden. Sobald der präformierte Komplex aufgehoben ist, kann SLP65 nicht zu den aktivierten BZR bzw. Syk gelangen, und damit ist die weitere Signalleitung unterbrochen. Für die B-Zelle bedeutet das, dass eine Aktivierung und Differenzierung nach Antigenerkennung stark beeinträchtigt bzw. aufgehoben ist, sobald der präformierte SLP65/CIN85/CD2AP-Komplex gestört ist.

In Zusammenarbeit mit Dr. Facundo Batista und Tim Schnyder (Cancer Research UK) konnte mittels der Kombination von „Lipid-bilayer“-basierter BZR-Stimulation und TIRF-Mikroskopie, die Kolokalisation von SLP65-wt mit den aktivierten „BCR-microclusters“ untersucht werden. Dazu wurden die oben beschriebenen rekonstituierten DT40-Zellen, welche SLP65-wt-GFP exprimierten, verwendet. Diese Zellen wurden auf sog. „Lipid-bilayers“ ausgesät, welche mit RFP-markierten IgMMolekülen gespickt waren. Sobald die Zellen mit den Fluoreszenzfarbstoff-markierten IgMMolekülen in Kontakt traten, kam es zur BZR-Quervernetzung und einem sog. „Spreading Process” (Fleire et al. 2006). Dieser dient zusammen mit der darauf folgenden Kontraktionsphase der B-Zellen der Antigen-Anreicherung in sog. „BCR-microclusters“. In diesen „BCR-microclusters“ werden dann zum einen Signale transduziert und zum anderen Antigene ins Zellinnere aufgenommen (Weber et al. 2008).

Mittels TIRF-Mikroskopie konnte die Kolokalisation von SLP65 und den aktivierten BZR in hoher Auflösung beobachtet werden. In diesem Experiment konnte zum ersten Mal in vivo gezeigt werden dass wildtypisches SLP65 nach BZR-Stimulation mit den „BCR-microclusters“ kolokalisiert (s. Fig. 5A, Oellerich et al. 2011, P.3628).

In weiteren Experimenten konnte in Zusammenarbeit mit Facundo Batista gezeigt werden, dass nur CIN85, aber nicht CD2AP nach Stimulation in die „BCR-microclusters“ rekrutiert wird (s. Fig. 5 B und 5D, Oellerich et al. 2011, P.3628). Diese Experimente wurden mit cDNA-Konstrukten von Vanessa Bremes durchgeführt. Diese Daten ergänzen die massenspektrometrischen und biochemischen Daten, die zwar alle potentiellen Interaktionen nachweisen können, allerdings nicht immer die in-vivo-Situation widerspiegeln. CIN85 scheint also dasjenige Protein zu sein, welches mit SLP65 interagieren muss, um es zur Plasmamembran zu rekrutieren.

Dies wird umso mehr deutlich, als dass CIN85 auch in SLP65-defizienten DT40-B-Zellen in die „microclusters“ rekrutiert wird (s. Fig. 5C, Oellerich et al. 2011, P.3628). Die CIN85-Rekrutierung ist also unabhängig von SLP65, während die von SLP65 in hohem Maße abhängig ist von CIN85. CIN85 ist also funktionell „upstream“ von SLP65 und damit ein neu identifizierter Schlüsselorganisator der proximalen BZR-Signalleitung.

Um direkt zu zeigen, dass CIN85 in B-Zellen in der Lage ist, Proteine zu den aktivierten BZR zu rekrutieren, habe ich in Zusammenarbeit mit Hanibal Bohnenberger SLP65-defiziente B-Zellen mit SLP76 oder der von mir entworfenen SLP76*-Variante rekonstituiert (s. Fig. 7A und 7B, Oellerich et 
al. 2011, P.3630). In SLP76* sind durch zielgerichtete Mutagenese der SLP76-cDNA insgesamt 5 Aminosäuren ausgetauscht, sodass drei PxxxPR-Motive, die normalerweise nicht in SLP76 vorhanden sind, entstehen. Bekanntermaßen kann wildtypisches SLP76 in B-Zellen nicht die Funktion von SLP65 übernehmen, da SLP76 das Transmembranprotein LAT benötigt, um zur Zellmembran rekrutiert zu werden (Wong et al. 2000). LAT wird in B-Zellen nicht exprimiert. Wenn nun aber durch die Einführung der PxxxPR-Motive SLP76* mit CIN85 interagiert, kann SLP76* in B-Zellen zum aktivierten BZR-Komplex rekrutiert werden und die $\mathrm{Ca}^{2+}$-Freisetzung in SLP65-defizienten Zellen wiederherstellen (s. Fig. 7C, 7D und 7E, Oellerich et al. 2011, P.3630). Dieses Experiment zeigt, dass CIN85 in der Lage ist, bestimmte Proteine in B-Zellen zu den aktivierten BZR zu rekrutieren. CIN85 ist damit maßgeblich an der Initiierung der BZR-abhängigen Signalleitung beteiligt, was eine bisher unbekannte Funktion dieses zentralen Adapterproteins darstellt. 


\section{Diskussion der Ergebnisse}

Meine Dissertation beschäftigt sich mit der vom B-Zell-Antigenrezeptor abhängigen Signaltransduktion. Dabei habe ich mittels verschiedener Methoden insbesondere die Funktionsweise des Adapterproteins SLP65 untersucht. Dieses Adapterprotein ermöglicht es dem BZR Signale im Zellinneren zu erzeugen; diese Signale können dann wiederum bestimmte Reaktionen der B-Zellen hervorrufen (Koretzky et al. 2006). So kann die erfolgreiche Antigenerkennung durch den BZR zur BZell-Aktivierung und Proliferation führen (Reth und Wienands 1997). Des Weiteren werden Differenzierungsprozesse durch BZR abhängige Signale gesteuert, wodurch letztlich funktionstüchtige Effektorzellen des Immunsystems wie z.B. Plasmazellen entstehen. Im Zuge der BZR-Stimulation kann allerdings auch Apoptose in den betreffenden B-Zellklonen hervorgerufen werden; dies geschieht z.B. bei der Erkennung von Autoantigenen. Allein diese Vielfalt an verschiedenen Reaktionen als Folge der BZR-Stimulation macht deutlich, dass die Kinetik und Intensität der Signale innerhalb der Zelle fein reguliert werden müssen; eine Dysregulation der vom BZR-abhängigen Signalleitung kann hingegen zu Immundefekten oder Erkrankungen aus dem onkologischen Formenkreis führen (Chun et al. 2008; Jumaa et al. 2003).

Zur Charakterisierung der SLP65-Funktionsweise habe ich neben anderen Methoden die Massenspektrometrie-basierte Proteinanalytik eingesetzt. Mittels dieser Methode konnte ich zeigen, dass SLP65 an 41 verschiedenen Aminosäureresten phosphoryliert wird. Damit ist SLP65 eines der am stärksten phosphorylierten Proteine, welche an der Signalleitung in Immunzellen beteiligt sind. Insgesamt 63\% der Phosphorylierungsstellen in SLP65 sind Serinreste; 22\% stellen Tyrosin- und 15\% Threoninreste dar. Große Phosphoproteom-Studien haben gezeigt, dass die durchschnittliche Phosphorylierung von Aminosäuren in eukaryotischen Zellen zu 86\% an Serin-, zu 12\% an Threoninund nur zu etwa $2 \%$ an Tyrosinresten stattfindet (Olsen et al. 2006). Die im Vergleich zum Durchschnitt deutlich verstärkte Tyrosinphosphorylierung von SLP65 spiegelt die proximale Position von SLP65 in der BZR-Signaltransduktion wider.

Nicht nur die große Anzahl der Phosphorylierungsstellen, sondern auch die komplexe Phosphorylierungskinetik sind ein wichtiger Hinweis darauf, dass auf der Ebene von SLP65 eine deutliche Regulation der BZR-Signalleitung stattfindet. Die Kombination von SILAC und Massenspektrometrie erlaubte die Bestimmung der Phosphorylierungskinetik von SLP65 in Abhängigkeit von der BZR-Stimulation. Die phosphorylierten Aminosäuren lassen sich hinsichtlich ihrer Phosphorylierungskinetik in fünf Gruppen einteilen, nämlich in a) frühe und transiente, b) frühe und bleibende, c) späte, d) herunterregulierte und e) konstante Phosphorylierungsstellen. Die Tatsache, dass SLP65 noch 20 Minuten nach der BZR-Stimulation phosphoryliert wird, zeigt, dass SLP65 nicht nur für die Initiation der Signale wichtig ist, sondern auch für deren Integration und Prozessierung.

Ein Beispiel für eine solche Signalprozessierung stellt die hierarchische Phosphorylierung von Serin173 und -170 dar. Diese führt nämlich zu einer verstärkten Aktivierung der MAP-Kinasen JNK und 
p38, was eine veränderte Gentranskription durch den Transkriptionsfaktor AP-1 zur Folge hat. Ich konnte zeigen, dass diese Regulation unabhängig von der $\mathrm{Ca}^{2+}$-Freisetzung stattfindet, welche wiederum von der SLP65-Tyrosinphosphorylierung abhängt. Somit kann die Phosphorylierung verschiedener Aminosäurereste eines Proteins verschiedene, voneinander unabhängige Signalleitungsprozesse steuern. Unklar bleibt dabei, ob alle SLP65-Moleküle im Zytosol von B-Zellen an den gleichen Stellen zur gleichen Zeit phosphoryliert werden, oder ob doch unterschiedlich phosphorylierte „SLP65 pools“ bestehen, welche verschiedene Funktionen ausführen. Die Ergebnisse der massenspektrometrischen Analyse von SLP65 sprechen eher für letzteres Modell. Wie in Tabelle 1 (Oellerich et al. 2009, P.1744) dargestellt, konnten die gleichen tryptischen SLP65-Peptide mit unterschiedlichem Phosphorylierungsstatus nachgewiesen werden. D.h., dass nicht alle 41 identifizierten Phosphoaminosäuren im selben SLP65-Molekül vorliegen, sondern dass SLP65 zu einem Zeitpunkt in verschiedenen Phosphorylierungszuständen existiert. Dies würde die Komplexizität der Signalleitung um ein Vielfaches erhöhen und damit eine weitere Dimension der intrazellulären Signalregulation darstellen. Hinweise dafür, dass Adapterproteine gleichzeitig in verschiedenen Proteinkomplexen vorliegen können, lieferten bereits systematische Studien, die Proteininteraktionsnetzwerke in Hefe untersuchten (Gavin et al. 2002).

Im Hinblick auf die Funktionsweise von SLP65 konnte bisher nicht geklärt werden, wie der $\mathrm{Ca}^{2+}$ Initiationskomplex zu seinem Wirkungsort nämlich der Zellmembran gelangt. SLP65 muss von der Kinase Syk an mehreren Tyrosinen phosphoryliert werden, um selbst aktiviert zu werden. An welchem Ort diese Interaktion zwischen Syk und SLP65 stattfindet, ist bisher unbekannt. Da Syk mit den aktivierten BZR interagiert, ist es wahrscheinlich, dass SLP65 im Zuge der Stimulation erst zu den aktivierten BZR gelangen muss, um dann dort selbst durch Syk aktiviert zu werden.

Bereits 1996 konnte gezeigt werden, dass präformierte Proteinkomplexe für eine effiziente Signalleitung in B-Zellen notwendig sind (Wienands et al. 1996). Die Komponenten dieser bereits vor der Stimulation vorliegenden Signalmodule konnten damals jedoch nicht identifiziert werden. Mittels quantitativer Proteomstudien konnte ich nun die stimulationsunabhängigen und -abhängigen SLP65Bindepartner identifizieren und zudem deren Interaktionskinetik bestimmen. Nach BZR-Stimulation konnte ich mehr als 20 Proteine als Teil des SLP65-Signalosoms identifizieren, während der präformierte SLP65-Komplex im Wesentlichen aus nur drei Proteinen, nämlich CIN85, CD2AP und SLP65, bestand. Ich konnte zeigen, dass die BZR-abhängige Reorganisation des Komplexes von diesem präformierten Komplex maßgeblich abhängt. Dazu habe ich ein Verfahren etabliert und angewandt, welches wir als „Reverse Proteomics“ bezeichnen (s. Kapitel 2.6). Es erlaubt Unterschiede in der Zusammensetzung zwischen wildtypischen Proteinkomplexen und solchen, in denen Punktmutationen vorliegen, zu ermitteln. Dieses Verfahren könnte in Zukunft insbesondere zur Erforschung dysregulierter Signaltransduktion im Rahmen von Erkrankungen z.B. aus dem onkologischen Formenkreis beitragen. „Reverse Proteomics“ erlaubte uns zu unterscheiden, welche Proteine des SLP65-Signalosoms in Anwesenheit der R-to-A-Mutationen in SLP65 dennoch an das 
Adapterprotein binden und welche hingegen nicht. Wie bereits beschrieben wurde in diesem Experiment deutlich, dass die präformierte Interaktion zwischen SLP65 und CIN85/CD2AP notwendig für die SLP65-Aktivierung ist. Dies konnte ich in weiteren funktionellen Studien weiter untermauern.

In-vivo-Studien belegten zudem, dass insbesondere CIN85 notwendig ist, um SLP65 zu den aktivierten BZR zu rekrutieren. Mit CIN85 habe ich somit einen neuen Effektor in der BZRvermittelten Signalleitung identifiziert. Eine solche „targeting“-Funktion von CIN85 im Rahmen der Signalinitiation wurde bisher in keinem anderem Zell- bzw. Rezeptorsystem beschrieben. Der genaue Mechanismus der CIN85-Membranrekrutierung ist zurzeit noch unklar. Eine Hypothese könnte sein, dass CIN85 mittels seines Interaktionspartners der Ubiquitin-Ligase Cbl zum BZR gelangt. Dazu passen Daten, die belegen, dass in B-Zellen aus cbl-defizienten Mäusen keine SLP65-Aktivierung stattfindet (Kitaura et al. 2007). Des Weiteren ist bekannt, dass CIN85 mittels seiner C-terminalen „Coiled-coil“-Domäne an ,phosphatidic acid“ (PA) binden kann (Zhang et al. 2009). PA entsteht als Membranlipid im Rahmen der BZR-Stimulation (Forssell et al. 2000) und könnte ebenfalls einen Modus der Stabilisierung von CIN85 an der Zellmembran darstellen. Weitere Experimente müssen folgen, um diese Hypothesen zu prüfen und die Funktionsweise von CIN85 in B-Zellen weiter zu charakterisieren. Da nun CIN85 als ein neuer wichtiger Effektor der BZR-Signalleitung identifiziert wurde, könnte man zudem nach Mutationen im cin85-Lokus in Patienten mit ALL, X-gekoppelter Agammaglobulinämie oder auch Autoimmunerkrankungen suchen.

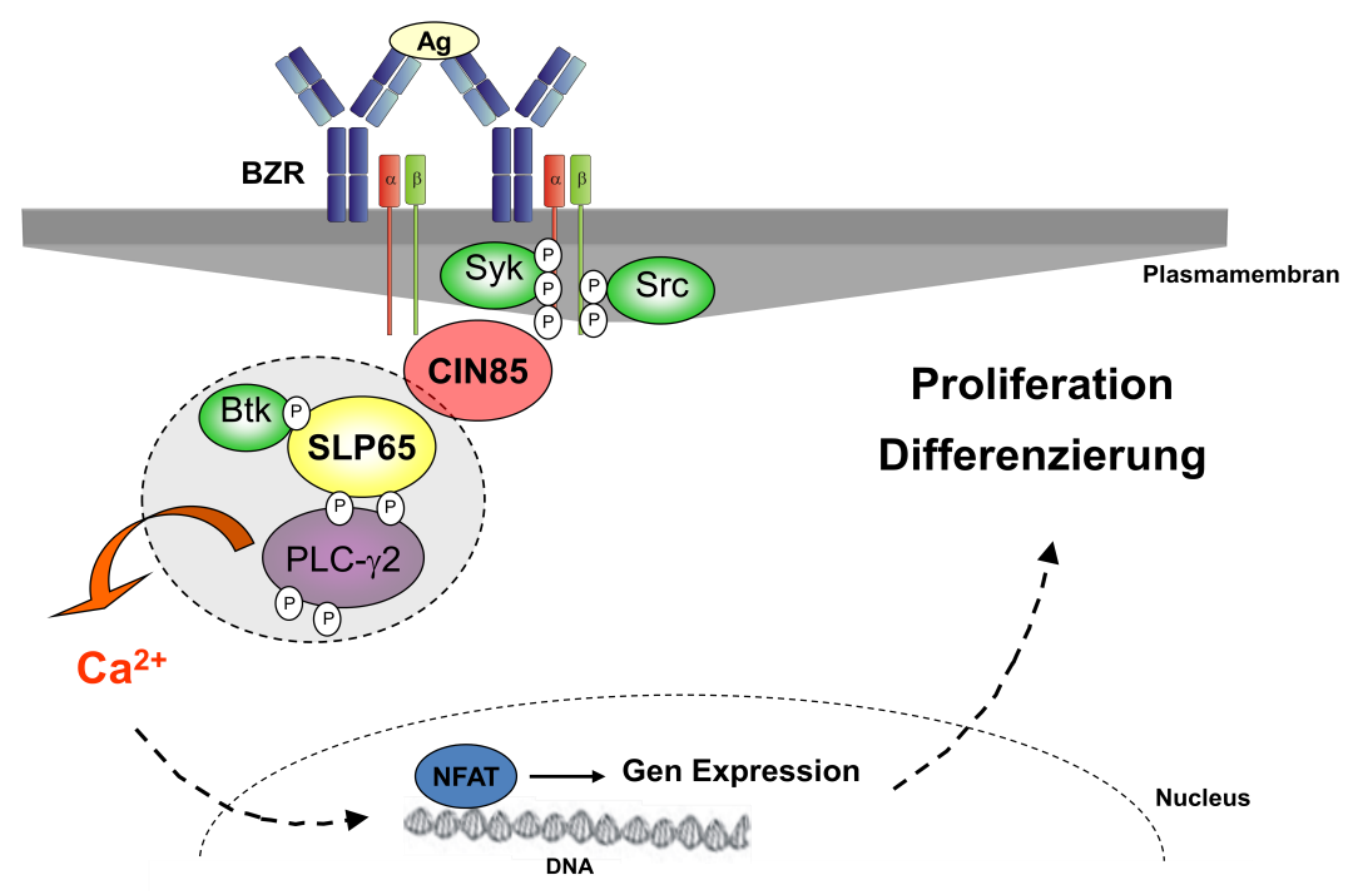




\section{Abb. 12: Signaltransduktion durch den BZR}

CIN85 bildet die Brücke zwischen der Tyrosinkinase Syk und dem Adapterprotein SLP65.

Die Proteomstudie hat neben CIN85 viele weitere Proteine als Teil des SLP65-Signalosoms identifiziert. Die Funktion dieser Proteine ist in B-Zellen weitgehend unbekannt und es bedarf einer weiteren funktionellen Charakterisierung. Selbiges trifft für die Vielzahl an neu identifizierten Phosphorylierungsstellen zu. Neben SLP65 habe ich auch andere Signalproteine in B-Zellen mit den beschriebenen Methoden untersucht. Dabei gelang es unter anderem, das dynamische Interaktionsnetzwerk von Grb2 zu ermitteln.

Zusammengefasst bilden meine Daten eine Grundlage für die weitere Erforschung der BZRabhängigen Signalleitung. Die funktionelle Charakterisierung von CIN85 als Organisator des SLP65Signalosoms leistet einen wichtigen Beitrag zum Verständnis der Signalleitung des BZR. Die Entschlüsselung des SLP65-Signalosoms hat neben CIN85 viele weitere bisher unbekannte Effektoren der BZR-abhängigen Signalleitung identifiziert. Die hier gezeigte Dynamik der Proteinphosphorylierung und der Proteinnetzwerke macht deutlich, dass die Signaltransduktion in BZellen einer starken Regulation unterliegt und zeitlich gesehen in verschiedenen Phasen organisiert ist.

Eine weitere Charakterisierung dieser Prozesse wird in Zukunft notwendig sein, um die Komplexität der Signalleitung besser zu verstehen und dann mittels pharmakologisch wirksamer Substanzen diese gezielt zu beeinflussen. Dies ist bereits in einigen Bereichen, wie z. B. in der Behandlung der chronischen myeloischen Leukämie, bereits gelungen; dort verhindert die Anwendung des Tyrosinkinase-(Bcr-abl)-inhibitors Imatinib (oder auch Dasatinib und Nilotinib) oftmals einen Progress der Erkrankung (Cortes et al. 2011). Entartete B-Zellen sind häufig Ursache von Lymphomen. Zielgerichtete Therapien, die spezifisch in aberrante Signalwege eingreifen, werden in diesem Bereich benötigt. Zur Entwicklung solcher Therapeutika ist ein Verständnis der physiologischen Signalwege in B-Zellen eine wichtige Voraussetzung.

Auch in anderen Bereichen der Medizin wie der Transplantationsimmunologie spielen B-Zellen eine herausragende Rolle. Heute weiß man, dass an einer späten Abstoßungsreaktion von Transplantaten neben T- auch B-Zellen maßgeblich beteiligt sind. Im Hinblick auf eine effektive Immunsuppression nach Organtransplantationen haben sich u.a. Calcineurin-Inhibitoren als wirksam erwiesen, indem sie insbesondere die T-Zell-Aktivierung inhibieren. Aufgrund der hohen Calcineurin-Expression in BZellen können Calcineurin-Inhibitoren nicht zur Suppression von B-Zellen eingesetzt werden. Andere Effektoren der durch den BZR regulierten Signalkaskaden müssen also pharmakologisch beeinflusst werden, um die B-Zell-Aktivierung effektiv zu inhibieren. Denkbar wäre z. B. eine Inhibierung des $\mathrm{Ca}^{2+}$-Initiationskomplexes, welcher erst eine Calcineurin-Aktivierung ermöglicht. Die weitere Erforschung der intrazellulären Signalwege in B-Zellen wird das Verständnis der B-Zell-Biologie auf molekularer Ebene erweitern und in Zukunft zur Entwicklung weiterer spezifischer Therapiemöglichkeiten in verschiedenen Bereichen der Medizin beitragen. 


\section{Literaturverzeichnis}

Abudula A, Grabbe A, Brechmann M, Polaschegg C, Herrmann N, Goldbeck I, Dittmann K Wienands J (2007): "SLP-65 signal transduction requires Src homology 2 domainmediated membrane anchoring and a kinase-independent adaptor function of Syk." J Biol Chem 282(39): 29059-29066

Ackermann JA, Radtke D, Maurberger A, Winkler TH Nitschke L (2011): "Grb2 regulates Bcell maturation, B-cell memory responses and inhibits B-cell $\mathrm{Ca}(2+)$ signalling." EMBO $\mathrm{J}$ in press

Blagoev B, Kratchmarova I, Ong SE, Nielsen M, Foster LJ Mann M (2003): "A proteomics strategy to elucidate functional protein-protein interactions applied to EGF signaling." Nat Biotechnol 21(3): 315-318

Blagoev B, Ong SE, Kratchmarova I Mann M (2004): "Temporal analysis of phosphotyrosine-dependent signaling networks by quantitative proteomics." Nat Biotechnol 22(9): 1139-1145

Burnet FM (1959): "Biological approach to carcinogenesis." Acta Unio Int Contra Cancrum 15(1): $31-34$

Casellas R, Shih TA, Kleinewietfeld M, Rakonjac J, Nemazee D, Rajewsky K Nussenzweig MC (2001): "Contribution of receptor editing to the antibody repertoire." Science 291(5508): 1541-1544

Chiu CW, Dalton M, Ishiai M, Kurosaki T Chan AC (2002): "BLNK: molecular scaffolding through 'cis'-mediated organization of signaling proteins." EMBO J 21(23): 6461-6472

Cheng PC, Dykstra ML, Mitchell RN Pierce SK (1999): "A role for lipid rafts in B cell antigen receptor signaling and antigen targeting." J Exp Med 190(11): 1549-1560

Chun JK, Lee TJ, Song JW, Linton JA Kim DS (2008): "Analysis of clinical presentations of Bruton disease: a review of 20 years of accumulated data from pediatric patients at Severance Hospital." Yonsei Med J 49 (1): 28-36

Cortes J, Hochhaus A, Hughes T Kantarjian H (2011): "Front-line and salvage therapies with tyrosine kinase inhibitors and other treatments in chronic myeloid leukemia." J Clin Oncol 29(5): 524-531

Cox J, Mann M (2008): "MaxQuant enables high peptide identification rates, individualized p.p.b.-range mass accuracies and proteome-wide protein quantification." Nat Biotechnol 26(12): 1367-1372

Cox J, Matic I, Hilger M, Nagaraj N, Selbach M, Olsen JV Mann M (2009): "A practical guide to the MaxQuant computational platform for SILAC-based quantitative proteomics." Nat Protoc 4(5): 698-705

Deutsch HF Fudenberg HH (1969): "Immunoglobulin structure and function." Adv Intern Med 15: 377-396 
Dikic I (2002): "CIN85/CMS family of adaptor molecules." FEBS Lett 529(1): 110-115

Dustin ML, Olszowy MW, Holdorf AD, Li J, Bromley S, Desai N, Widder P, Rosenberger F, van der Merwe PA, Allen PM, et al. (1998): "A novel adaptor protein orchestrates receptor patterning and cytoskeletal polarity in T-cell contacts." Cell 94(5): 667-677

Engelke M, Engels N, Dittmann K, Stork B Wienands J (2007): "Ca(2+) signaling in antigen receptor-activated B lymphocytes." Immunol Rev 218: 235-246

Engels N, Wollscheid B Wienands J (2001): "Association of SLP-65/BLNK with the B cell antigen receptor through a non-ITAM tyrosine of Ig-alpha." Eur J Immunol 31(7): 2126-2134

Flaswinkel H Reth M (1994): "Dual role of the tyrosine activation motif of the Ig-alpha protein during signal transduction via the B cell antigen receptor." EMBO J 13(1): 8389

Fleire SJ, Goldman JP, Carrasco YR, Weber M, Bray D Batista FD (2006): "B cell ligand discrimination through a spreading and contraction response." Science $\underline{312(5774) \text { : }}$ $738-741$

Foletta VC, Segal DH Cohen DR (1998): "Transcriptional regulation in the immune system: all roads lead to AP-1." J Leukoc Biol 63(2): 139-152

Forssell J, Nilsson A Sideras P (2000): "Reduced formation of phosphatidic acid upon B-cell receptor triggering of mouse B-lymphocytes lacking Bruton's tyrosine kinase." Scand J Immunol 52(1): 30-38

Fu C, Turck CW, Kurosaki T Chan AC (1998): "BLNK: a central linker protein in B cell activation." Immunity $\underline{9}(1):$ 93-103

Gavin AC, Bosche M, Krause R, Grandi P, Marzioch M, Bauer A, Schultz J, Rick JM, Michon AM, Cruciat CM, et al. (2002): "Functional organization of the yeast proteome by systematic analysis of protein complexes." Nature $\underline{415}$ (6868): 141-147

Goitsuka R, Fujimura Y, Mamada H, Umeda A, Morimura T, Uetsuka K, Doi K, Tsuji S Kitamura D (1998): "BASH, a novel signaling molecule preferentially expressed in B cells of the bursa of Fabricius." J Immunol 161(11): 5804-5808

Gold MR (2008): "B cell development: important work for ERK." Immunity 28 (4): 488-490

Goodnow CC, Cyster JG, Hartley SB, Bell SE, Cooke MP, Healy JI, Akkaraju S, Rathmell JC, Pogue SL Shokat KP (1995): "Self-tolerance checkpoints in B lymphocyte development." Adv Immunol 59: 279-368

Goodnow CC, Vinuesa CG, Randall KL, Mackay F Brink R (2010): "Control systems and decision making for antibody production." Nat Immunol 11(8): 681-688

Grabbe A Wienands J (2006): "Human SLP-65 isoforms contribute differently to activation and apoptosis of B lymphocytes." Blood 108(12): 3761-3768 
Herzog S, Reth M Jumaa H (2009): "Regulation of B-cell proliferation and differentiation by pre-B-cell receptor signalling." Nat Rev Immunol 9(3): 195-205

Ishiai M, Kurosaki M, Pappu R, Okawa K, Ronko I, Fu C, Shibata M, Iwamatsu A, Chan AC Kurosaki T (1999): "BLNK required for coupling Syk to PLC gamma 2 and Rac1JNK in B cells." Immunity 10(1): 117-125

Jacob J, Kelsoe G, Rajewsky K Weiss U (1991): "Intraclonal generation of antibody mutants in germinal centres." Nature 354(6352): 389-392

Janeway CA, Jr. Medzhitov R (2002): "Innate immune recognition." Annu Rev Immunol 20: $197-216$

Jumaa H, Wollscheid B, Mitterer M, Wienands J, Reth M Nielsen PJ (1999): "Abnormal development and function of B lymphocytes in mice deficient for the signaling adaptor protein SLP-65." Immunity 11(5): 547-554

Jumaa H, Bossaller L, Portugal K, Storch B, Lotz M, Flemming A, Schrappe M, Postila V, Riikonen P, Pelkonen J, et al. (2003): "Deficiency of the adaptor SLP-65 in pre-B-cell acute lymphoblastic leukaemia." Nature 423(6938): 452-456

Kim KM, Alber G, Weiser P Reth M (1993): "Differential signaling through the Ig-alpha and Ig-beta components of the B cell antigen receptor." Eur J Immunol 23(4): 911-916

Kitaura Y, Jang IK, Wang Y, Han YC, Inazu T, Cadera EJ, Schlissel M, Hardy RR Gu H (2007): "Control of the B cell-intrinsic tolerance programs by ubiquitin ligases Cbl and Cbl-b." Immunity 26(5): 567-578

Kohler F, Storch B, Kulathu Y, Herzog S, Kuppig S, Reth M Jumaa H (2005): "A leucine zipper in the $\mathrm{N}$ terminus confers membrane association to SLP-65." Nat Immunol 6(2): 204-210

Kopp EB Medzhitov R (1999): "The Toll-receptor family and control of innate immunity." Curr Opin Immunol 11(1): 13-18

Koretzky GA, Abtahian F Silverman MA (2006): "SLP76 and SLP65: complex regulation of signalling in lymphocytes and beyond." Nat Rev Immunol $\underline{6}(1): 67-78$

Kowanetz K, Szymkiewicz I, Haglund K, Kowanetz M, Husnjak K, Taylor JD, Soubeyran P, Engstrom U, Ladbury JE Dikic I (2003): "Identification of a novel proline-arginine motif involved in CIN85-dependent clustering of $\mathrm{Cbl}$ and down-regulation of epidermal growth factor receptors." J Biol Chem 278(41): 39735-39746

Kulathu Y, Hobeika E, Turchinovich G Reth M (2008): "The kinase Syk as an adaptor controlling sustained calcium signalling and B-cell development." EMBO J 27(9): 1333-1344

Lam KP, Kuhn R Rajewsky K (1997): "In vivo ablation of surface immunoglobulin on mature B cells by inducible gene targeting results in rapid cell death." Cell 90(6): 1073-1083 
Larsen MR, Thingholm TE, Jensen ON, Roepstorff P Jorgensen TJ (2005): "Highly selective enrichment of phosphorylated peptides from peptide mixtures using titanium dioxide microcolumns." Mol Cell Proteomics 4⑺: 873-886

Leo A, Wienands J, Baier G, Horejsi V Schraven B (2002): "Adapters in lymphocyte signaling." J Clin Invest 109(3): 301-309

Loffert D, Schaal S, Ehlich A, Hardy RR, Zou YR, Muller W Rajewsky K (1994): "Early Bcell development in the mouse: insights from mutations introduced by gene targeting." Immunol Rev 137: 135-153

Machesky LM, Goldschmidt-Clermont PJ Pollard TD (1990): "The affinities of human platelet and Acanthamoeba profilin isoforms for polyphosphoinositides account for their relative abilities to inhibit phospholipase C." Cell Regul 1(12): 937-950

Minegishi Y, Rohrer J, Coustan-Smith E, Lederman HM, Pappu R, Campana D, Chan AC Conley ME (1999): "An essential role for BLNK in human B cell development." Science 286(5446): 1954-1957

Molfetta R, Belleudi F, Peruzzi G, Morrone S, Leone L, Dikic I, Piccoli M, Frati L, Torrisi MR, Santoni A, et al. (2005): "CIN85 regulates the ligand-dependent endocytosis of the IgE receptor: a new molecular mechanism to dampen mast cell function." $\mathrm{J}$ Immunol 175(7): 4208-4216

Mortensen P, Gouw JW, Olsen JV, Ong SE, Rigbolt KT, Bunkenborg J, Cox J, Foster LJ, Heck AJ, Blagoev B, et al. (2010): "MSQuant, an open source platform for mass spectrometry-based quantitative proteomics." J Proteome Res 9(1): 393-403

Neumann K, Oellerich T, Urlaub H Wienands J (2009): "The B-lymphoid Grb2 interaction code." Immunol Rev 232: 135-149 (Publikation B)

Oellerich T, Bremes V, Neumann K, Bohnenberger H, Dittmann K, Hsiao H, Engelke M, Schnyder T, Batista F, Urlaub H, et al. (2011): "The B cell antigen receptor signals through a preformed transducer module of SLP65 and CIN85" EMBO J 30(17): 3620-3634 (Publikation C)

Oellerich T, Gronborg M, Neumann K, Hsiao H, Urlaub H Wienands J (2009): "SLP-65 phosphorylation dynamics reveals a functional basis for signal integration by receptorproximal adaptor proteins." Mol Cell Proteomics $\underline{8}(7)$ : 1738-1750 (Publikation A)

Olsen JV, Blagoev B, Gnad F, Macek B, Kumar C, Mortensen P Mann M (2006): "Global, in vivo, and site-specific phosphorylation dynamics in signaling networks." Cell 127(3): 635-648

Ong SE, Blagoev B, Kratchmarova I, Kristensen DB, Steen H, Pandey A Mann M (2002): "Stable isotope labeling by amino acids in cell culture, SILAC, as a simple and accurate approach to expression proteomics." Mol Cell Proteomics 1(5): 376-386

Pappu R, Cheng AM, Li B, Gong Q, Chiu C, Griffin N, White M, Sleckman BP Chan AC (1999): "Requirement for B cell linker protein (BLNK) in B cell development." Science 286(5446): 1949-1954 
Patterson HC, Kraus M, Kim YM, Ploegh H Rajewsky K (2006): "The B cell receptor promotes $\mathrm{B}$ cell activation and proliferation through a non-ITAM tyrosine in the Igalpha cytoplasmic domain." Immunity $\underline{25}$ (1): 55-65

Pawson T (2007): "Dynamic control of signaling by modular adaptor proteins." Curr Opin Cell Biol 19(2): 112-116

Pawson T, Raina M Nash P (2002): "Interaction domains: from simple binding events to complex cellular behavior." FEBS Lett 513(1): 2-10

Peruzzi G, Molfetta R, Gasparrini F, Vian L, Morrone S, Piccoli M, Frati L, Santoni A Paolini R (2007): "The adaptor molecule CIN85 regulates Syk tyrosine kinase level by activating the ubiquitin-proteasome degradation pathway." J Immunol 179(4): 20892096

Rao A (2009): "Signaling to gene expression: calcium, calcineurin and NFAT." Nat Immunol 10(1): $3-5$

Rao A Hogan PG (2009): "Calcium signaling in cells of the immune and hematopoietic systems." Immunol Rev 231(1): 5-9

Reichlin A, Hu Y, Meffre E, Nagaoka H, Gong S, Kraus M, Rajewsky K Nussenzweig MC (2001): "B cell development is arrested at the immature B cell stage in mice carrying a mutation in the cytoplasmic domain of immunoglobulin beta." J Exp Med 193(1): 1323

Reth M (1989): "Antigen receptor tail clue." Nature $\underline{338(6214): ~ 383-384 ~}$

Reth M Wienands J (1997): "Initiation and processing of signals from the B cell antigen receptor." Annu Rev Immunol 15: 453-479

Rudd CE (1999): "Adaptors and molecular scaffolds in immune cell signaling." Cell 96(1): 58

Ruland J Mak TW (2003a): "From antigen to activation: specific signal transduction pathways linking antigen receptors to NF-kappaB." Semin Immunol 15(3): 177-183

Ruland J Mak TW (2003b): "Transducing signals from antigen receptors to nuclear factor kappaB." Immunol Rev 193: 93-100

Sanchez M, Misulovin Z, Burkhardt AL, Mahajan S, Costa T, Franke R, Bolen JB Nussenzweig M (1993): "Signal transduction by immunoglobulin is mediated through Ig alpha and Ig beta." J Exp Med 178(3): 1049-1055

Shih NY, Li J, Karpitskii V, Nguyen A, Dustin ML, Kanagawa O, Miner JH Shaw AS (1999): "Congenital nephrotic syndrome in mice lacking CD2-associated protein." Science 286(5438): 312-315 
Shih NY, Li J, Cotran R, Mundel P, Miner JH Shaw AS (2001): "CD2AP localizes to the slit diaphragm and binds to nephrin via a novel C-terminal domain." Am J Pathol 159(6): 2303-2308

Sohn HW, Tolar P, Jin T Pierce SK (2006): "Fluorescence resonance energy transfer in living cells reveals dynamic membrane changes in the initiation of B cell signaling." Proc Natl Acad Sci U S A 103(21): 8143-8148

South MA, Cooper MD, Hong R Good RA (1967): "The IgA antibody system." Curr Top Dev Biol 2: 191-222

Stavnezer J, Guikema JE Schrader CE (2008): "Mechanism and regulation of class switch recombination." Annu Rev Immunol 26: 261-292

Stork B, Engelke M, Frey J, Horejsi V, Hamm-Baarke A, Schraven B, Kurosaki T Wienands J (2004): "Grb2 and the non-T cell activation linker NTAL constitute a $\mathrm{Ca}(2+)-$ regulating signal circuit in B lymphocytes." Immunity 21(5): 681-691

Stork B, Neumann K, Goldbeck I, Alers S, Kahne T, Naumann M, Engelke M Wienands J (2007): "Subcellular localization of Grb2 by the adaptor protein Dok-3 restricts the intensity of Ca2+ signaling in B cells." EMBO J 266(4): 1140-1149

Take H, Watanabe S, Takeda K, Yu ZX, Iwata N Kajigaya S (2000): "Cloning and characterization of a novel adaptor protein, CIN85, that interacts with c-Cbl." Biochem Biophys Res Commun 268(2): 321-328

Tomlinson S (1993): "Complement defense mechanisms." Curr Opin Immunol 5 $\underline{1}(1)$ : 83-89

Tonegawa S (1983): "Somatic generation of antibody diversity." Nature 302(5909): 575-581

von Behring, E., and Kitasato, S. (1890): "Über das Zustandekommen der DiphterieImmunität und der Tetanus-Immunität bei Thieren." Dtsch Med Wochenschr 49

Watanabe S, Take H, Takeda K, Yu ZX, Iwata N Kajigaya S (2000): "Characterization of the CIN85 adaptor protein and identification of components involved in CIN85 complexes." Biochem Biophys Res Commun 278(1): 167-174

Weber M, Treanor B, Depoil D, Shinohara H, Harwood NE, Hikida M, Kurosaki T Batista FD (2008): "Phospholipase C-gamma2 and Vav cooperate within signaling microclusters to propagate B cell spreading in response to membrane-bound antigen." J Exp Med 205(4): 853-868

Wienands J (2000): "The B-cell antigen receptor: formation of signaling complexes and the function of adaptor proteins." Curr Top Microbiol Immunol 245(1): 53-76

Wienands J, Larbolette O Reth M (1996): "Evidence for a preformed transducer complex organized by the B cell antigen receptor." Proc Natl Acad Sci U S A 93(15): 78657870 
Wienands J, Schweikert J, Wollscheid B, Jumaa H, Nielsen PJ Reth M (1998): "SLP-65: a new signaling component in B lymphocytes which requires expression of the antigen receptor for phosphorylation." J Exp Med 188(4): 791-795

Wong J, Ishiai M, Kurosaki T Chan AC (2000): "Functional complementation of BLNK by SLP-76 and LAT linker proteins." J Biol Chem 275(42): 33116-33122

Xu S, Tan JE, Wong EP, Manickam A, Ponniah S Lam KP (2000): "B cell development and activation defects resulting in xid-like immunodeficiency in BLNK/SLP-65-deficient mice." Int Immunol 12(3): 397-404

Zhang J, Zheng X, Yang X Liao K (2009): "CIN85 associates with endosomal membrane and binds phosphatidic acid." Cell Res 19(6): 733-746 